\title{
1 Rainfall interception and the coupled surface water and energy balance
}

3 Albert I. J. M. van Dijk ${ }^{1 *}$, John H. Gash ${ }^{2}$, Eva van Gorsel ${ }^{3}$, Peter D. Blanken ${ }^{4}$, Alessandro Cescatti ${ }^{5}$, 4 Carmen Emmel $^{6}$, Bert Gielen ${ }^{7}$, Ian Harman ${ }^{3}$, Gerard Kiely $^{8}$, Lutz Merbold ${ }^{7}$, Leonardo Montagnani ${ }^{9}$, 5 Eddy Moors $^{10}$, Marilyn Roland ${ }^{6}$, Matteo Sottocornola ${ }^{11}$, Andrej Varlagin ${ }^{12}$, Christopher A. Williams ${ }^{13}$, Georg Wohlfahrt ${ }^{14}$

\footnotetext{
${ }^{1}$ Fenner School for Environment \& Society, Australian National University, Canberra, Australia

* corresponding author: postal address: Linnaeus way, 0200 Canberra, ACT, Australia. E-mail: albert.vandijk@anu.edu.au. Telephone: (+61 02) 612 52197;

${ }^{2}$ Centre for Ecology and Hydrology, Wallingford, UK

${ }^{3}$ CSIRO Oceans and Atmosphere Flagship, Canberra, Australia

${ }^{4}$ Department of Geography, University of Colorado at Boulder, Boulder, USA

${ }^{5}$ European Commission, Joint Research Centre, Institute for Environment and Sustainability, Ispra, Italy

${ }^{6}$ Department of Environmental Systems Science, Institute of Agricultural Sciences, ETH Zurich, Zurich, Switzerland

${ }^{7}$ University of Antwerp, Wilrijk, Belgium

${ }^{8}$ Civil and Environmental Engineering Dept., and Environmental Research Institute, University College Cork, Ireland

${ }^{9}$ Faculty of Science and Technology, Free University of Bolzano, and Forest

Services, Autonomous Province of Bolzano, Bolzano, Italy

${ }^{10}$ Alterra Wageningen UR, Netherlands

${ }^{11}$ Department of Science, Waterford Institute of Technology, Waterford, Ireland

${ }^{12}$ A.N. Severtsov Institute of Ecology and Evolution, Russian Academy of Sciences, Moscow, Russia

${ }^{13}$ Graduate School of Geography, Clark University, Worcester, USA

${ }^{14}$ Institute of Ecology, University of Innsbruck, Innsbruck, Austria
} 


\section{Abstract}

10 Evaporation from wet canopies $(E)$ can return up to half of incident rainfall back into the atmosphere

11 and is a major cause of the difference in water use between forests and short vegetation. Canopy water

12 budget measurements often suggest values of $E$ during rainfall that are several times greater than

13 those predicted from Penman-Monteith theory. Our literature review identified potential issues with

14 both estimation approaches, producing several hypotheses that were tested using micrometeorological

15 observations from 128 FLUXNET sites world-wide. The analysis shows that FLUXNET eddy-

16 covariance measurements tend to provide unreliable measurements of $E$ during rainfall. However, the

17 other micrometeorological FLUXNET observations do provide clues as to why conventional Penman-

18 Monteith applications underestimate $E$. Aerodynamic exchange rather than radiation often drives $E$

19 during rainfall, and hence errors in air humidity measurement and aerodynamic conductance

20 calculation have considerable impact. Furthermore, evaporative cooling promotes a downwards heat

21 flux from the air aloft as well as from the biomass and soil; energy sources that are not always

22 considered. Accounting for these factors leads to $E$ estimates and modelled interception losses that are

23 considerably higher. On the other hand, canopy water budget measurements can lead to overestimates

24 of $E$ due to spatial sampling errors in throughfall and stemflow, underestimation of canopy rainfall

25 storage capacity, and incorrect calculation of rainfall duration. There are remaining questions relating

26 to horizontal advection from nearby dry areas, infrequent large-scale turbulence under stable

27 atmospheric conditions, and the possible mechanical removal of splash droplets by such eddies. These

28 questions have implications for catchment hydrology, rainfall recycling, land surface modelling, and

29 the interpretation of eddy-covariance measurements.

31 Keywords: rainfall interception; wet canopy evaporation; FLUXNET; water use; evapotranspiration;

32 Penman-Monteith theory 


\section{Introduction}

36 Rainfall interception is the fraction of rain that falls onto vegetation but never reaches the ground,

37 instead evaporating from the wet canopy. The most direct way to measure rainfall interception

38 evaporation is through the construction of weighing lysimeters, which is a major undertaking for

39 forests (Dunin et al., 1988). Therefore interception loss (the amount of rainfall lost to wet canopy

40 evaporation) has usually been derived as the residual between event gross rainfall measured above the

41 canopy or in a nearby clearing, and net rainfall, the latter calculated as the sum of separately measured

42 throughfall and stemflow below the canopy. In his pioneering paper, Horton (1919) recognised that (i)

43 the fractions of rainfall becoming throughfall and stemflow both vary as a function of storm size and

44 canopy characteristics, (ii) canopy water storage capacity, storm duration and the rate of wet canopy

45 evaporation $\left(E\right.$ in $\left.\mathrm{mm} \mathrm{h}^{-1}\right)$ during rainfall are the important variables determining interception loss;

46 (iii) the interception process can be conceptualised to consist of two components: wet canopy

47 evaporation during rainfall followed by drying of the canopy once rainfall has stopped; (iv) wind can

48 shed water from the canopy, but equally can increase $E$; and $(v)$ in the absence of snow, the fractional

49 interception loss from evergreen vegetation appears stable throughout the year, suggesting that, at

50 least for Horton's site in New York state, USA, event-average rainfall rate $\left(R\right.$ in $\left.\mathrm{mm} \mathrm{h}^{-1}\right)$ and $E$ both

51 increase in summer in approximate proportion. Research since has generally confirmed and refined

52 these observations (see benchmark papers reprinted in Gash and Shuttleworth, 2007). Law (1957)

53 combined throughfall and stemflow measurements with lysimeter drainage measurements to establish

54 a water budget for spruce and pasture. He concluded that the forests had substantially higher rainfall

55 interception losses and, as a consequence, produced less drainage and streamflow.

56 Nearly a century of further water budget measurements have emphasised the role of vegetation type in

57 determining the magnitude of rainfall interception. Forests typically intercept 10-30\% (but sometimes

58 up to half) of the rainfall and rapidly return it to the atmosphere, whereas short vegetation intercepts

59 less rainfall (e.g., Crockford and Richardson, 2000; Horton, 1919; Leyton et al., 1967; Roberts, 1999).

60 This difference goes far in explaining why forest establishment is commonly observed to decrease

61 (and removal increase) streamflow, at least in small catchment experiments (e.g., Van Dijk et al.,

62 2012). However, the physical processes and atmospheric conditions that allow such a large fraction of

63 rainfall to be returned to the atmosphere are poorly understood. In simulation models, rainfall

64 interception is usually estimated in one of two ways (Muzylo et al., 2009): many conceptual

65 hydrological models assume a fixed ratio between 'net' and 'gross' rainfall, without any attempt to

66 reconcile the evaporation rate implied by the water budget $\left(E_{W B}\right)$ with the constraint of balancing the

67 energy budget. Alternatively, more detailed process hydrology and land surface models may include a

68 canopy water balance model following the concepts originally introduced by Rutter et al. (1971).

69 These latter models are coupled to the energy balance if they use evaporation rates based on Penman-

70 Monteith theory $\left(E_{P M}\right)$. 
71 Numerous studies have combined field measurements of the canopy water budget with sub-daily or

72 event-based interception modelling. By comparing gross and net rainfall for a series of storm events,

73 one can use graphical or regression approaches to derive an 'effective' $\bar{E} / \bar{R}$ ratio (i.e., of event-

74 average $E$ and $R$; cf. Gash, 1979) for multiple events and a mean canopy rainfall storage capacity, $S$

75 (in $\mathrm{mm}$ ), where $S$ is defined as the minimum depth of water needed to saturate the canopy.

76 Alternatively, these parameters can be found by fitting the interception model against gross and net

77 rainfall measurements per event (Gash et al., 1995) or time step (Rutter et al., 1971). Less commonly,

78 interception has been estimated by comparing rainfall inputs to changes in total water storage in a

79 column of soil with trees (Dunin et al., 1988). More often than not, the different methods produce

80 results that are difficult to explain in terms of the energy balance, in that inferred $E$ exceeds $E_{P M}$ by a

81 factor of two or more (Holwerda et al., 2012; Schellekens et al., 1999). In other words, the

82 observations cannot be reconciled within a coupled water and energy balance.

83 The objective of this study is to better understand the reasons for the discrepancy between energy and

84 water balance approaches in determining interception loss. This discrepancy is reflected in the

85 uncertainty of flux estimates; in fact, commonly rainfall interception is not even considered as a

86 separate process in the estimation of evapotranspiration by flux tower eddy covariance measurements,

87 remote sensing and modelling methods alike. Better understanding the coupled water and energy

88 balance during rainfall may also have important ramifications for land-use management and water

89 policies, and for our understanding of the role of forests in the climate system (Bonan, 2008). For

90 example, if the rate of vapour return and the rate of energy withdrawal from the boundary layer are

91 greater than current land surface models predict, this may affect the rainfall generation downwind

92 predicted by weather and climate models (Blyth et al., 1994). This in turn would suggest that the

93 implications of vegetation change for rainfall and water resources availability downwind might need

94 to be reconsidered. Conversely, if the true evaporative flux is much lower than estimated from field

95 measurements, it might require a revision of currently held assumptions about the impact of land-

96 cover change on the catchment water balance.

97 Several hypotheses have been proposed to explain the discrepancy between water budget and energy

98 balance methods, but to the best of our knowledge they have not been systematically assessed or

99 tested. This was the primary motivation for this study.

100 This article is structured as follows. The theoretical framework to analyse the energy balance theory

101 during rainfall is provided in Section 2. The global FLUXNET 'La Thuile' database (Baldocchi,

102 2008; Baldocchi et al., 2001) provided unique opportunities to test several of the hypotheses. Details

103 on data selection and the list of 128 sites are provided in Annex A, whereas methodological

104 challenges in measurement and data processing are discussed in Section 3. The proposed causes for

105 the discrepancy in estimated wet canopy evaporation rates are identified in Section 4, and

106 subsequently tested in the following sections. Specifically, issues in applying Penman-Monteith 
107 theory are investigated in Section 5, whereas issues in the application of rainfall interception models

108 are examined in Section 6. Finally, we summarise our main conclusions in Section 7. Each hypothesis

109 tested required its own data analysis with a varying level of methodological complexity.

110 To maintain readability we described the data analysis methods and results together, and relegated

111 some more intricate aspects of the methodology to appendices B (canopy heat flux estimation) and C

112 (simplified rainfall interception model).

113

114 2. Theory

115 Rutter (1967) was the first to apply the Penman (1952) equation to rainfall interception. With later

116 modifications introduced by Monteith (1981), the Penman-Monteith equation can be used to estimate 117 latent heat flux, $\lambda E\left(\mathrm{~W} \mathrm{~m}^{-2}\right)$ as:

$$
\lambda E_{P M}=\frac{\Delta}{\Delta+\gamma^{\prime}} A+\frac{\rho c_{p}}{\Delta+\gamma^{\prime}} g_{a}\left(e_{s}-e\right)
$$

119 with

$120 \quad \gamma^{\prime}=\gamma\left(1+g_{a} / g_{s}\right)$.

121 where $\Delta\left(\mathrm{Pa} \mathrm{K}^{-1}\right)$ is the slope of the saturation water vapour pressure curve at air temperature $T(\mathrm{~K})$,

$122 \gamma \square$ and $\gamma\left(\mathrm{Pa} \mathrm{K}^{-1}\right)$ are the adjusted and original psychrometric constants, $A$ ( $\left(\mathrm{W} \mathrm{m}^{-2}\right)$ is the available

123 energy, $\rho\left(\mathrm{kg} \mathrm{m}^{-3}\right)$ the specific density of air, $c_{p}\left(\mathrm{~J} \mathrm{~kg}^{-1} \mathrm{~K}^{-1}\right)$ the specific heat of air at constant

124 temperature, $g_{a}$ and $g_{s}\left(\mathrm{~m} \mathrm{~s}^{-1}\right)$ the aerodynamic and surface conductances, respectively, while the

125 difference between saturation vapour pressure at ambient temperature $e_{s}(\mathrm{~Pa})$ and the actual vapour

126 pressure $e(\mathrm{~Pa})$ is the vapour pressure deficit or VPD. Rutter (1967) pointed out that for a wet canopy,

127 the latent heat flux is no longer limited by stomatal conductance. Therefore $g_{s}$ should approach

128 infinity and $\gamma \square$ becomes numerically equal to $\gamma$. It is noted that in a partially wet but poorly

129 ventilated canopy, surface conductance may still be finite, as found for Amazonian rainforest by

130 Czikowsky and Fitzjarrald (2009). The available energy $A$ is given by (all in $\mathrm{W} \mathrm{m}^{-2}$ ):

$131 \quad A=R_{n}-G-Q$

132 where $R_{n}$ is net all-wave radiation, $G$ is the ground heat flux and $Q$ is the sum of all minor energy

133 sources and sinks, including any change in heat storage in the canopy air, $Q_{a}$, and in the biomass, $Q_{v}$,

134 as well as energy used for photosynthesis and produced by other metabolic processes. The last two

135 terms are ignored in the present context, but the fluxes $Q_{v}$ and $Q_{a}$ may not be negligible, as will be 136 discussed. 
137 Net radiation $R_{n}$ is typically small during rainfall, because of cloud cover during the day and because

138 rain can equally occur during the night. Rutter (1967) found that wet canopy evaporation could be

139 about four times greater than transpiration rates would have been under the same atmospheric

140 conditions. Importantly, he recognised that the latent heat flux associated with evaporation on days

141 with rain exceeded $A$ and concluded that "energy is obtained from the air"; in other words, there is a

142 downwards sensible heat flux $(H)$ and/or cooling of the ambient air. This situation is also predicted by

143 the Penman-Monteith equation if the aerodynamic component of $\lambda E_{P M}$ (the second term) is greater

144 than the radiation component (the first term), since the energy balance $A=H+\lambda E$ demands that (cf. Eq.

145 (1a)):

$H_{P M}=A-\lambda E=\frac{\gamma^{\prime}}{\Delta+\gamma^{\prime}} A-\frac{\rho c_{p}}{\Delta+\gamma^{\prime}} g_{a}\left(e_{s}-e\right)$

Furthermore, using the bulk aerodynamic approach of Eq. (1a), $H$ is also given by (cf. Penman, 1952):

$$
H=\rho c_{p} g_{a}\left(T_{s}-T\right)
$$

149 where $T_{\mathrm{s}}(\mathrm{K})$ is the temperature of the surface (e.g., the canopy). A downward sensible heat flux

150 requires that the surface is cooler than the air (Eq. (4)). Pereira et al. (2009) demonstrated that, at least under conditions of low irradiance, the wet crowns of isolated trees cool to temperatures very close to wet bulb temperature, implying that the effective $g_{s}$ is indeed very high (cf. Eqs. (1a and b). Rutter (1967) measured that wet leaves were up to $1 \mathrm{~K}$ cooler than the air above. In turn, the air above the wet canopy was itself on average $1 \mathrm{~K}$ cooler than at a reference climate station nearby, suggesting that the greater aerodynamic roughness of the forest led to greater evaporative cooling. This was initially dismissed as a forest edge effect, until Stewart (1977) presented measurements over an extensive forest area that also showed a negative $H$ of up to about $50 \mathrm{~W} \mathrm{~m}^{-2}$. The FLUXNET database also bears this out. Table 1 lists average values of $H$ reported for a wide range of sites in the FLUXNET data base, measured by three-dimensional anemometers. Although reported $H$ values during rain events need to be interpreted with some caution (see Section 3), the average $H$ for all periods with rainfall was negative for $80 \%$ of sites $(N=108)$, with an average $H$ of $-12 \pm 16 \mathrm{~W} \mathrm{~m}^{-2}$ for sites with tall

162 vegetation ( $>3 \mathrm{~m}, N=59)$ and $-6 \pm 8 \mathrm{~W} \mathrm{~m}^{-2}$ for sites with short vegetation (>1.5 m, $N=49$; Table 1).

163 The greatest negative $H\left(-31 \mathrm{~W} \mathrm{~m}^{-2}\right)$ was determined also for the tallest forest (AU-Wac, $70 \mathrm{~m}$ tall). 
166 Because of the typically negative $H$, Stewart (1977) suggested that large-scale advection must occur,

167 which he argued could have been supplied from adjoining land areas with a dry canopy. Alternatively,

168 Shuttleworth and Calder (1979) argued that the lack of surface control and the strong atmospheric

169 coupling of a wet forest canopy means that high $E$ can be sustained by "the considerable sensible heat

170 already stored, or presently being released by the precipitation process, in the lower levels of the

171 atmosphere". They also commented that sensible heat advection will be common under such

172 conditions, and point out that when there is little radiation, the mere fact that saturation deficits in and

173 near the wet canopy are greater than zero in itself provides proof that sensible heat is supplied.

174 Finally, they argue that the occurrence of cloud formation and rainfall is necessarily associated with

175 vertical air mass movement and associated advection.

176 Since the 1970s, some of these important insights appear to have faded from the collective

177 conscience. For example, the majority of land surface models use conventional Penman-Monteith

178 theory in a way that tends to predict rainfall interception losses that are lower than field experimental

179 knowledge suggests, with unknown consequences for weather and climate modelling. Similarly,

180 methods to estimate total evapotranspiration from remote sensing usually appear to ignore the

181 unresolved wet canopy energy balance problem, and indeed frequently ignore rainfall interception

182 loss altogether; Guerschman et al. (2009) and Miralles et al. (2010) are exceptions.

184 3. Eddy-covariance measurement during rainfall

185 In the last few decades, eddy-covariance techniques have provided increasingly sophisticated and

186 widespread measurements of ecosystem-level land surface-atmosphere fluxes, including $\lambda E$ and $H$.

187 The theory underpinning eddy-covariance analysis can be found elsewhere (e.g., Aubinet et al., 2012)

188 but, essentially, it relies on analysing the covariance between high-frequency observed vertical air

189 movement and scalar concentration. Measurements are made with sonic three-dimensional

190 anemometers co-located with open- or closed-path infrared gas analysers. In theory, eddy-covariance

191 measurements could be used to independently verify $E$. However, there does not appear to be

192 consensus, or indeed much published research at all, on the validity of standard eddy-covariance

193 measurement and analysis techniques during rainfall, or methods to detect and/or correct the affected

194 flux data. This is perhaps surprising, given the likelihood of erroneous measurements by at least some

195 of the instruments and given that standard data analysis and gap-filling methods and protocols have

196 been developed to deal with a variety of other measurement issues (e.g., Moffat et al., 2007). The lack

197 of such a standard approach may also explain why it is easy to find examples of analyses that either

198 accept latent heat flux measurements during rainfall without question, or replace these using gap-

199 filling strategies that interpolate the data, essentially assuming that flux behaviour is similar to that

200 under dry canopy conditions. Both assumptions introduce potentially very large errors in ET 
estimates, a particular concern if the resulting longer-term estimates are reported without caveats or even are used to evaluate model ET estimates (Van Dijk and Warren, 2010).

There are good reasons why FLUXNET eddy-covariance measurements may be of questionable validity during rainfall. While many models of sonic anemometers employ hydrophobic material on the sensors and automatic spike removal, water on the sensor surfaces and raindrops falling through the sensor path still affect instrument readings. Mizutani et al. (1997) tested the performance of sonic anemometers in laboratory conditions and found that up to $2.5 \mathrm{~mm}$ depth on the sonic sensor head caused wind speed and sensible heat flux measurement errors within 1\%. Simulated rainfall intensities less than $10 \mathrm{~mm} \mathrm{~h}^{-1}$ also did not appear to affect measurements much, although higher intensities did. Similar results have been obtained for other sonic anemometer instruments (Cabral et al., 2010; Gash et al., 1999). By contrast, open path gas analysers do not appear to function at all well for water vapour during rainfall. Burba et al. (2010) found that $75 \%$ of open path gas analyser data were lost during rainfall conditions. Closed-path analysers with long unheated intake tubes suffer from other measurement errors due to condensation and re-evaporation in the intake tube (so-called frequency loss). The resulting underestimation of latent heat flux can be large and increases exponentially with humidity (Fratini et al., 2012; Ibrom et al., 2007; Mammarella et al., 2009). Czikowsky and Fitzjarrald (2009) used closed-path measurements during and after rainfall over a tropical rainforest, but did not report on the accuracy of the measurements. Measurement errors during rainfall may also explain why a recent synthesis of global FLUXNET eddy-covariance data found that total ET from forests is less than from grasslands under similar climate conditions (Williams et al., 2012), in contrast with catchment studies.

The quality of eddy-covariance heat flux estimates is commonly assessed by calculating the energy balance ratio (EBR), i.e. the sum of $\lambda E$ and $H$ divided by $A$, for a selected period (Stoy et al., 2013; Wilson et al., 2002). This method does not necessarily work well for wet canopy conditions, as it was shown that $\lambda E$ and $H$ will often have opposite signs (i.e., an upwards latent and downwards sensible heat flux). Temporarily assuming $Q=0$ (i.e., $A=R_{n}-G$; cf. Eq. (2)), energy balance calculations for the FLUXNET sites suggest an average 'missing' energy loss under dry conditions of $16 \pm 13 \mathrm{~W} \mathrm{~m}^{-2}$ for tall and $11 \pm 13 \mathrm{~W} \mathrm{~m}^{-2}$ for short vegetation, producing mean EBR values of $80 \%$ and $86 \%$, respectively (Table 1). However, during wet conditions, the situation degrades with missing fluxes of $28 \pm 20 \mathrm{~W} \mathrm{~m}^{-2}$ for tall and $18 \pm 17 \mathrm{~W} \mathrm{~m}^{-2}$ for short vegetation, producing respective EBR values of $37 \%$ (note the negative sign) and $36 \%$. These numbers get considerably worse if $Q$ is accounted for (see Section 5.2), suggesting that $\lambda E$ derived from FLUXNET eddy-covariance measurements during and shortly after rainfall are too low.

Alternatively, some studies have avoided gas analyser measurements during rainfall by calculating $\lambda E$ as the energy balance residual, i.e., $\lambda E=A-H$. Following this approach, Herbst et al. (2008) calculated $E$ that could be reconciled with $E_{P M}$ as well as with $E_{W B}$. However, Van der Tol et al. (2003) did not 
237 find good agreement. We calculated $\lambda E$ as the energy balance residual for the FLUXNET data, again

238 temporarily ignoring $Q$. For sites with tall vegetation, this produced an average value of $45 \pm 18 \mathrm{~W} \mathrm{~m}^{-2}$

239 instead of the $17 \pm 15 \mathrm{~W} \mathrm{~m}^{-2}$ listed in Table 1. For short vegetation, the average latent flux was $35 \pm 17$

$240 \mathrm{~W} \mathrm{~m} \mathrm{~m}^{-2}$ instead of the reported $17 \pm 14 \mathrm{~W} \mathrm{~m}^{-2}$. However, it is not clear if it is appropriate to assume that

241 all energy balance errors simply can be attributed to $\lambda E$ to produce a reliable estimate (Foken, 2008).

242 In particular, the importance of low frequency turbulence in the commonly stable atmospheric

243 conditions during rainfall is unknown. The influence of low frequency flux contributions in eddy-

244 covariance data processing can be problematic. The measured covariance is usually split into the

245 product of means (interpreted as the advection term) and the fluctuations (the eddy fluxes) by 'block

246 time averaging', commonly for 30 minute intervals (Finnigan et al., 2003). However, Sakai et al.

247 (2001) found that eddies with a return interval of more than 40 minutes can contribute to up to $40 \%$ of

248 surface fluxes during light wind conditions around midday over a temperate forest. This means that

249 30-minute time block-averaging can introduce substantial errors and lead to underestimates of $H$. This

250 in turn would mean that the 'real' energy balance residual, and therefore $\lambda E$, would be greater than

251 calculated. Overall, therefore, FLUXNET eddy-covariance flux data during rainfall and shortly

252 thereafter need to be treated as suspect.

254 4. Proposed causes for the discrepancy in estimated wet canopy evaporation rates

255 The most common way to determine $E$ is via a canopy water budget, where rainfall is measured above

256 the canopy, and throughfall and stemflow beneath it. Gross rainfall measurements can be affected by

257 the influence of the gauge itself on the wind field; Sevruk (2006) suggests a typical systematic under-

258 catch of ca. 2-10\%, depending on height above the surface or canopy. However, an over-catch in

259 gross rainfall measurement would be needed to explain the inferred high rainfall interception rates.

260 This may occur where gauges are placed in sheltered locations, e.g., in a gap within a forest (see

261 Sevruk, 2006 for further discussion).

262 Spatial throughfall and stemflow sampling errors can lead to overestimation, but more commonly,

263 underestimation of throughfall and stemflow, depending on the vegetation structure and the way it

264 affects the occurrence of drip points and funnelling of excess water from the canopy (Holwerda et al.,

265 2006; Lloyd and Marques, 1988). In some experimental studies, stemflow has been ignored

266 altogether. Stemflow usually represents less than $2 \%$ of the canopy water balance, but in extreme

267 cases it can amount to more than $10 \%$ of total rainfall (Levia and Frost, 2003; Llorens and Domingo,

268 2007). Experimental design and sampling issues can explain some of the high rainfall interception

269 rates inferred, and will usually lead to an overestimation of interception. However, carefully designed

270 water budget studies with a large number of roving throughfall gauges and measurements of stemflow 
still tend to find higher interception rates than predicted from $E_{P M}$ (e.g., Holwerda et al., 2006). Thus, such water budget errors can only provide a partial explanation.

Other hypotheses can be categorised in different ways. Several hypotheses question the validity of the $E_{P M}$ estimates, or at least the assumptions made or data used, if not Penman-Monteith theory itself. Others address possible errors arising from the explicit or implicit assumptions in the rainfall interception models (Table 2). These are discussed in the next two sections.

\section{[TABLE 2 HERE]}

\section{Errors in applying Penman-Monteith theory}

The Penman-Monteith theory invokes a number of assumptions. Predominantly these are that (1) all transport terms (of energy and water) are accounted for; (2) the site can be considered horizontally homogeneous; and (3) that the flow is statistically horizontally homogeneous and stationary. These three assumptions allow evaporation to be modelled as a one-dimensional system and ensure consistency through time of the relationships between the measurable meteorological variables, the fluxes of interest and the model coefficients, especially with the aerodynamic conductance. Each assumption, however, can be challenged by the specifics of the site and the rainfall event.

\subsection{Unaccounted energy advection}

Shuttleworth and Calder (1979) observed that unexpectedly high $E$ appeared to occur mainly at maritime sites, whereas interception measured at locations further inland were more in line with $E_{P M}$. This led to the hypothesis that horizontal advection of sensible heat from the ocean could provide a source of additional energy not accounted for in the conventional use of the Penman-Monteith model. Further evidence of a maritime influence was later found by Schellekens et al. (1999). Advection of energy from the ocean requires an onshore wind that brings in air with a higher temperature and/or VPD, or both. Roberts et al. (2005) suggested that such a process is unlikely for most locations as it would require a horizontal temperature gradient of several $\mathrm{K}$ per $100 \mathrm{~m}$ (although they did not present the calculation). Moreover, a locally generated 'sea breeze' would normally bring in cooler and moister air rather than warmer and drier air, and therefore a large-scale synoptic mechanism would be required. However, advected energy does not need to come from the ocean: particularly under convective conditions there will be warmer and drier air available from nearby areas without rain (Stewart, 1977). Energy advection does not invalidate Penman-Monteith theory, but energy advected horizontally below the level of (vertical) energy balance measurement would be unaccounted for. This normally occurs only on the edges between contrasting surfaces, although strong convective storm 
305 cells may also draw in air laterally. On the other hand, vertical energy advection from the higher

306 boundary layer should still be measured as a negative $H$ and reflected in air temperature and humidity.

307 Alternatively, Holwerda et al. (2012) argued that the previously postulated maritime-continental

308 contrast may have been misinterpreted and that high $E$ may in fact be a feature of enhanced

309 topographic roughness and exposure in complex, mountainous terrain, which happened to coincide

310 with proximity to the ocean in previous studies. The increased relief enhances boundary-layer mixing

311 compared to flat terrain and creates local variations in wind speed depending on wind direction and,

312 potentially, lateral advection of energy below the eddy covariance instruments. Numerical and

313 theoretical studies demonstrate that the deviations in air flow and turbulence in the boundary layer, as

314 it responds to even minor topography, challenge many of the assumptions underpinning both Penman-

315 Monteith and eddy covariance theory (e.g., Raupach and Finnigan 1997, Huntingford et al. 1998,

316 Finnigan 2004). These issues are even more severe where there is a tall canopy, which generates

317 multiple interactions between the turbulence and the terrain-induced circulation (Finnigan and Belcher

318 2004, Belcher et al. 2008, 2012, Ross 2014). The impacts of these processes are contingent on the

319 specifics of the site and the rain event, and therefore in conclusion, it would seem unlikely that

320 advection alone can explain why $E_{P M}$ estimates should be systematically too low.

\subsection{Underestimation of biomass and ground heat release}

323 Release of thermal energy stored in the forest, both in the vegetation biomass $\left(Q_{v}\right)$ and in the air below

324 the measurement level $\left(Q_{a}\right)$, may also provide an additional source of energy for evaporation (Moors,

325 2012). These heat fluxes can be estimated by considering the pre-storm air temperature, the structure

326 and dimensions of the biomass elements and their surface temperature, which for a wet canopy may

327 be assumed to be intermediate between air temperature and wet bulb temperature, depending on

328 ventilation. Michiles and Gielow (2008) measured forest heat storage changes in an Amazonian rain

329 forest and found that it could contribute as much as $200 \mathrm{~W} \mathrm{~m}^{-2}$ due to rapid cooling of the forest. Such

330 a high heat flux is presumably limited to the beginning of a storm and unlikely to be sustained for a

331 prolonged period. Where forest heat storage has been estimated, it typically represents a very small

332 flux over the duration of an entire storm (Gash et al., 1999; Pereira et al., 2009). $Q$ can be simulated

333 using physical models that require detailed knowledge of forest structure, biomass and physical

334 properties (Haverd et al., 2007; Kobayashi et al., 2012). We did not have access to such observations

335 for the numerous sites, and therefore used a simplified method to obtain an order of magnitude

336 estimate of $Q$ (see Appendix B). The resulting estimates of $Q$ are an average release of $29 \pm 31 \mathrm{~W} \mathrm{~m}^{-2}$

337 during rainfall periods for sites with tall vegetation ( $>3 \mathrm{~m}, N=59$ ), and a (negligible) $0.8 \pm 1.3 \mathrm{~W} \mathrm{~m}^{-2}$

338 for sites with short vegetation $(<1.5 \mathrm{~m}, N=49)$. For tall vegetation, this means that $Q$ is typically larger

339 than $H\left(-12 \pm 16 \mathrm{~W} \mathrm{~m}^{-2}\right)$ and of similar magnitude to $R_{n}\left(31 \pm 22 \mathrm{~W} \mathrm{~m}^{-2}\right)$. In other words, it is an 
important source of evaporative energy. The biomass heat flux $Q_{v}$ is responsible for an average $93 \%$ of total $Q$ across sites, primarily because $Q_{a}$ is the net result of the counteracting effects of cooling air temperature and increasing moisture content (Eq. (A.1)). The overall $Q$ was largely explained by the estimated rate of biomass temperature change $\left(-1.6 \mathrm{~K} \mathrm{~h}^{-1}\right.$ on average) and the height of the vegetation; their product explained $99 \%$ of the variance in total $Q$ (cf. Eq. (B.2)). The site with the highest average $Q$ during rainfall periods $\left(222 \mathrm{~W} \mathrm{~m}^{-2}\right)$ was also the tallest forest in the database (AU-Wac). Unfortunately, the accuracy of $Q$ estimates could not be tested. Given the assumptions about surface temperature, it probably represents an upper estimate. Accounting for $Q$ resulted in an increase in $\lambda E_{P M}$ for tall vegetation from $82 \pm 86 \mathrm{~W} \mathrm{~m}^{-2}$ to $108 \pm 102 \mathrm{~W} \mathrm{~m}^{-2}$; i.e. a modest increase of $17 \%$.

An upward ground heat flux $(G)$ may also be expected during rainfall. In theory, this could add energy to the canopy air and so potentially help increase evaporation. Values of $G$ reported in the FLUXNET database suggest an average upward heat flux of $2 \pm 8 \mathrm{~W} \mathrm{~m}^{-2}$ for tall vegetation, representing $8 \%$ of $R_{n}$. For short vegetation, the average upward heat flux is $6 \pm 11 \mathrm{~W} \mathrm{~m}^{-2}$, equivalent to $28 \%$ of $R_{n}$. (It is noted that $G$ reported in the FLUXNET database is often derived from heat flux plates and may not always account for heat storage in the soil above the flux plate). It follows that $G$ might be a modest but arguably non-negligible source of evaporative energy during rainfall.

\subsection{Errors in air humidity measurement}

Calculating $E_{P M}$ requires observations of VPD during rainfall. In the FLUXNET data, this is most commonly calculated from relative humidity $(\mathrm{RH})$ measured by capacitor sensors, but these are not sensitive in humid air and can be affected by rain splash and condensation on the radiation shields. This can have considerable influence on $E_{P M}$ estimates through Eq. (1). For example, Wallace and McJannet (2006) calculated that a $2 \% \mathrm{RH}$ reduction can increase $E_{P M}$ by $31 \%$. The reported mean RH during rainfall was $90 \pm 5 \%$ across the FLUXNET sites compared to $72 \pm 11 \%$ during dry periods. To assess the influence of RH errors, $E_{P M}$ was calculated using the observed RH as well as with RH reduced by $2 \%$, simulating the effect of a systematic bias. Reducing relative humidity by $2 \%$ inevitably increased estimated $\lambda E_{P M}$, by an average $34 \pm 23 \%$ across sites, or from an average $72 \pm 78$ to $92 \pm 76 \mathrm{~W} \mathrm{~m}^{-2}$ across all sites $(N=108)$. The variation was large, however, with a maximum relative increase of 2.3 times for one site (US-FPe), from 7 to $19 \mathrm{~W} \mathrm{~m}^{-2}$. We cannot assess whether there might be a systematic bias in the RH values reported in the FLUXNET database; systematic evaluation against a more accurate sensor during rainfall would be required (e.g., using a cooled mirror dew point hygrometer; cf. Schmidt et al., 2012). An apparent drift in annual maximum relative humidity of a few percent over several years has been observed for some FLUXNET sites, suggesting that such errors are certainly conceivable (Dr. M. Sottocornola, pers. comm.). 


\subsection{Underestimation of aerodynamic conductance}

Vertical air exchange is important during wet canopy conditions, as $E$ is driven by aerodynamic energy and the associated downward $H$. Dunin et al. (1988) analysed forest water storage changes measured by a weighing lysimeter and hypothesised that updrafts during storms might be responsible for the high $E$ they inferred from the lysimeter water budget. Particularly before the onset and during the early stages of a thunderstorm, strong updrafts can occur depending on the convective power of the storm. Complex terrain typically enhances boundary-layer mixing compared to flat terrain and imposes terrain-scale variation to the aerodynamic conductance (e.g. Raupach and Finnigan 1997). . Other researchers also highlight the importance of site exposure to wind (e.g., Van Dijk and Bruijnzeel, 2001b). Both convective and orographic updrafts would seem potentially efficient mechanisms to transport moisture and enhance $E$ by drawing in drier and/or warmer air, laterally or from higher up in the atmosphere, or both. They also challenge the assumption of consistency in the bulk-aerodynamic relationship, however.

All the above processes may enhance vertical air exchange, and hence increase the aerodynamic conductance, beyond that predicted by Monin-Obukhov similarity theory (MOST) (Holwerda et al., 2012). This is a potentially important source of error in $E_{P M}$ calculations, as the usual method to quantify the aerodynamic conductance, and that taken here, assumes a logarithmic wind speed profile based on MOST (Thom, 1975). This estimate of the aerodynamic conductance $g_{a T}$ is determined from the (horizontal) wind speed measured at a reference height as (e.g., Shuttleworth, 2012):

$$
g_{a T}=\frac{k u_{*}}{\ln \left(\frac{z-d}{z_{0 s}}\right)-\psi_{s}}
$$

with

$$
u_{*}=\frac{k u_{z}}{\ln \left(\frac{z-d}{z_{0 m}}\right)-\psi_{m}}
$$

where $k(0.40)$ is von Kármán's constant, $d(\mathrm{~m})$ the zero displacement length, $z_{0 m}$ and $z_{0 s}(\mathrm{~m})$ the roughness lengths for the transfer of momentum and scalars (i.e., heat and water vapour density), respectively, and $\psi_{m}$ and $\psi_{s}$ the stability corrections for momentum and scalar transfer, respectively. The latter are sometimes calculated, but often assumed negligible. The values of $d$ and $z_{0 m}$ cannot be determined without wind profile measurements. Following Rutter et al. (1971), it is usually assumed that $d=0.75 h$ and $z_{0}=0.1 h$, where $h$ is the canopy height (but see Gash et al., 1999, for an observationbased approach). (Commonly reported values of $z_{0 s} / z_{0 m}$ are $1 / 12$ to $1 / 2$. Testing showed that the actual value chosen had little influence and so here we used an intermediate ratio of 1/7.) Furthermore, the 
adoption of a single $z_{0 s}$ for heat and vapour transport implies that they have the same plane of origin and that this origin is fixed, which may not always be the case (Moors, 2012). Errors in any of these assumptions may be particularly important during rainfall: when the surface has a finite surface conductance, $g_{a}$ will occur both in the numerator and the denominator of the aerodynamic term of the Penman-Monteith equation (Eq (1)) and therefore errors in $g_{a}$ may not have a large effect, particularly if $g_{a} \gg g_{s}$. However under wet canopy conditions $g_{a}$ disappears from the denominator and hence errors in its estimation have more influence.

As three-dimensional wind speed measurements are made at the FLUXNET sites, errors in the application of the above approach may be deduced from a comparison of $g_{a T}$ and $g_{a U}$. Site values for $h$ and $z$ to calculate $g_{a T}$ were obtained from the primary references (Appendix A), from the site investigators, and from multi-site studies listing these variables (Amiro et al., 2006; Chen et al., 2009; Curtis et al., 2002; Rebmann et al., 2005; Richardson et al., 2006; Stoy et al., 2006; Wang et al., 2008; Wilson et al., 2002). Friction velocity $\left(u_{*}\right)$ can be derived directly from sonic wind speed measurements (Gash et al., 1999) and used to calculate aerodynamic conductance $\left(g_{a U}\right)$ with:

$$
g_{a U}=\frac{u_{*}}{\frac{u_{z}}{u_{*}}+\frac{1}{k} \ln \left(\frac{z_{0 m}}{z_{0 s}}\right)-\frac{\psi_{s}}{k}}
$$

The resulting mean $g_{a U}$ and $g_{a T}$ values across all sites are similar, but the relationship between the two is poor $\left(r^{2}=0.26\right.$, Figure 1). This emphasises the assumptions underpinning the two respective methods, and the challenge in predicting the wind speed profile in the case of $g_{a T}$. The $\lambda E_{P M}$ values calculated with $g_{a U}$ were not systematically higher or lower than those calculated with $g_{a T}$; on average the former was $1.05 \pm 0.37$ times greater than the latter. Including the stability correction (following Paulson, 1970) increased $g_{a U}$ by $1.5 \%$ on average but increases and decreases both occurred, depending on the dominant sign of $H$, and changes were small, with extremes of $-4 \%$ and $+6 \%$. It follows that assumptions in the calculation of $g_{a}$ following Thom (1975) can certainly introduce large errors, but underestimates of $\lambda E_{P M}$ appear about as likely as overestimates.

\section{[FIGURE 1 HERE]}

Both approaches to calculate $g_{a}$ still require MOST to be valid. In addition to the issues raised above and the possibility of systematic advection raised (Section 5.1), there are other reasons why this may not be the case. MOST invokes assumptions concerning the scales characterising the turbulent flow; 
specifically, that $u_{*}$ is the only important velocity scale, and that height $(z-d)$ and the Obukhov length are the important length scales. At several FLUXNET sites, especially those with tall canopies, observations may be taken in the roughness sub-layer. In this layer the turbulence is also characterised by length scales related to the surface. For example, over tall canopies the mixing layer instability that occurs at canopy top (e.g., Raupach et al. 1996) implies that a length scale linked to canopy density needs to be included in the analysis. Typically, the mixing layer instability leads to enhanced turbulent mixing and, correspondingly, $g_{a U}$ and $g_{a T}$ would be expected to underestimate the true aerodynamic conductance. Corrections to MOST for this tall canopy effect have been developed for dry conditions (e.g., Harman and Finnigan, 2007, 2008) but require calibration against site data for accuracy. Furthermore, turbulence during rainfall is additionally impacted through two other processes: the presence of rain droplets provides a large surface area for viscous dissipation, and falling rain imposes a drag on the atmosphere. Both processes add further length scales to the problem, and an appropriate correction method is yet to be developed and demonstrated.

Finally, wind speed $u_{z}$ needs to be correctly measured. Errors can occur if wind speeds are not measured directly above the canopy, but at a site with less exposure, e.g., in a forest gap or at a less exposed airport or climate station nearby, as is quite common in canopy water budget studies. The wind speed may also be underestimated if the event-average wind speed is assumed equal to daytime or daily average wind speeds on the day, or on dry days, as is a common practice.

In summary, the errors in the estimation of $g_{a}$ are easily made, can be of considerable magnitude, and have an important influence on $E_{P M}$ estimates.

\subsection{Mechanical water transport}

Even more difficult to evaluate is the effect of rain splash on the return of water to the atmosphere. Dunin et al. (1988) (see Dunkerley, 2009) and later Murakami (2006) point out that drops falling onto the canopy produce small impact droplets that can remain suspended in the air for long enough to partially or wholly evaporate before reaching the ground. For example, Murakami (2006) calculated that droplets of $<50 \mu \mathrm{m}$ diameter are likely to completely or largely evaporate when falling from a tall forest canopy. Ghadiri and Payne (1988) measured the size distribution of impact droplets formed by a $6 \mathrm{~mm}$ diameter drop hitting different surfaces; from the data they tabulate it can be calculated that drops of $<1 \mathrm{~mm}$ diameter represent at least $10 \%$ of the total volume of impacting droplets.

Measurements by Bassette and Bussière (2008) show that considerably more than half the volume of a large drop can be scattered in splash droplets when hitting a leaf. The largest number of droplets are produced when large drops are sliced, e.g., on leaf edges or petioles, and while large drops are relatively few in natural rainfall, they are ubiquitous in throughfall dripping through successive layers of the canopy (Dunkerley, 2009). However, the associated increase of the evaporating surface does 
not necessarily increase the latent heat flux, as surface conductance is already assumed to be infinitely large, whereas the aerodynamic conductance of the canopy should not be affected by the presence of splash droplets. In other words, $E$ is ultimately controlled by the ability of the turbulent boundary layer to transport water vapour away from the surface, rather than by the area of the evaporating surface.

The observation that (i) rainfall onto a canopy can produce many small droplets and (ii) strong vertical updrafts can occur during rainfall, suggests that updrafts can potentially also play a role in enhancing rainfall evaporation rates. The upwards vertical air movement may slow down sufficiently small impact droplets, or even transport them back into the atmosphere above the rainfall measurement level. This could create further opportunities for the droplets to evaporate, or to be swept up by falling raindrops and return to the surface, to be measured once again as rainfall. The mechanics appear to be feasible, as drops of 0.5 and $1 \mathrm{~mm}$ diameter have a maximum fall velocity of only 2 and $4 \mathrm{~m} \mathrm{~s}^{-1}$, respectively (Gunn and Kinzer, 1949), and updrafts of this strength (equivalent to a gentle breeze) occur frequently in the turbulent conditions associated with thunderstorms, at least above the canopy. Detecting this process may be possible using disdrometer measurements above the canopy, recording water droplet sizes and fluxes in both upward and downward motions down to the scale of fine-scale droplets that can be suspended by eddy motions. The existence of this process would not invalidate $E_{P M}$, but would add an additional mechanical vertical transport flux. It would go towards explaining the greater difference between rainfall above and below a tall and rough canopy, when compared to shorter vegetation.

\subsection{Summary}

Based on the foregoing analysis, we can predict the energy balance during rainfall using the PenmanMonteith equation to estimate $\lambda E_{P M}$ and $H_{P M}$ (Eqs. (1-3)), and accounting for $Q$ and $G$, as well as using measured $g_{a U}$. The resulting average $\lambda E_{P M}$ is not hugely different from 'conventional' PenmanMonteith based estimates $\left(\lambda E_{P M o}\right)$, but both are several times larger than the results of eddy-covariance measurements $\left(\lambda E_{E C}\right)$ (Table 3$)$. It is noted that downward $H_{P M}$ predicted by Penman-Monteith theory is considerably greater than that derived from the eddy-covariance measurements (Table 3). Moreover, these estimates do not account for several of the identified potential issues, such as humidity measurement errors, horizontal advection below the measurement level, problems using MOST, the influence of infrequent eddies, and mechanical transport.

\section{[TABLE 3 HERE]}


507 6. Errors in applying rainfall interception models

508 6.1. Underestimation of canopy rainfall storage

509 When estimating $E$ by fitting an interception model to event-total values of interception loss, there can

510 be a degree of functional equivalence (or 'parameter equifinality'; Beven, 1993) between $E$ during

511 rainfall and canopy rainfall storage capacity $(S)$, from which evaporation may continue after rainfall

512 has ceased. Therefore, underestimation of $S$ a priori is likely to be compensated by overestimation of

$513 E$. Because event-total throughfall and stemflow can be measured more easily and cheaply than their

514 instantaneous rates, the event-based analytical rainfall interception model (Gash, 1979; Gash et al.,

515 1995) has been applied more commonly than the dynamic model from which it was derived (Rutter et

516 al., 1971). The event-based analytical rainfall interception model has two particularly important

517 parameters that need to be estimated, $S$ and ratio $\bar{E} / \bar{R}$, and due to functional equivalence, an error in

518 one can lead to a compensating error in the other. For example, the graphical envelope method of

519 Leyton et al. (1967) to derive $S$ from event gross and net rainfall measurements inevitably leads to

520 underestimates.

521 Field methods to estimate $S$ also have their issues, however. Some have pointed at the large rainfall

522 storage capacity of tree bark and epiphytes (Herwitz, 1985; Wallace and McJannet, 2006), although

523 study of the water balance of epiphyte mosses by Hölscher et al. (2004) demonstrated that their

524 effectiveness in increasing interception losses is limited by the degree to which they dry out in

525 between storms. Similar arguments can be made for other water-retaining materials in the canopy.

526 The implication is that $S$ is likely overestimated if the total amount of water that such materials will

527 hold is assumed to evaporate. The importance of assumptions about $S$ is revisited in Section 6.3.

\subsection{Overestimation of rainfall rate}

530 The correct estimation of $E_{W B}$ from the ratio $\bar{E} / \bar{R}$ is contingent on accurate specification of $R$, and thus 531 an overestimate of $R$ could explain why $E_{W B}$ might be overestimated. The Gash model is based on the 532 assumption that the canopy has dried out between events. If the time interval adopted to separate 533 successive storms is too short for this to be true, then effective storm duration will be underestimated 534 and hence $R$ and $E$ will be overestimated (Wallace and McJannet, 2006). Furthermore, $R$ is normally 535 measured with tipping bucket rain gauges that have discrete $0.1-0.5 \mathrm{~mm}$ accumulation increments. If $536 R$ per time step is less than this increment, then the instrument will not register rainfall during every 537 time interval and errors in estimated storm duration can result. Storm duration errors can change $R$ 538 estimates by more than $50 \%$, given that storm separation times used in the literature can vary from 2 
539 to 6 hours (Wallace and McJannet, 2006). This effect was calculated for all FLUXNET sites with 540 rainfall data. Half hours with rainfall in excess of $0.25 \mathrm{~mm}$ were clustered together in one event if 541 they were separated between 0.5 and 24 hours. The overall average rainfall intensity $R$ was calculated 542 as the total rainfall divided by the total duration of all events, including the intra-storm intervals 543 without rainfall (Figure 3a). The reduction in $R$ with increased separation time was similar for all 544 sites; $R$ for 1 hour separation time $\left(R_{l}\right)$ was on average 1.46 times greater than for 6 hour separation 545 time $\left(R_{6}\right)$, varying from 1.14 (US-Wrc) to 2.04 (CA-Obs) times. It follows that assumptions about the 546 time required for the canopy to dry up can indeed have a considerable influence on $R$. The impact of 547 assuming shorter canopy drying times on estimates of total interception loss is mitigated by the fact 548 that the reduction in evaporation during the event can be partially compensated by an increase in 549 evaporation after the event, as the total number of events will increase if the separation time is 550 shortened (Figure 2b). Underestimating canopy drying time will however still lead to an overestimation of $E$ during rainfall and so can partially explain the discrepancy with $E_{P M}$ estimates.

[FIGURE 2 HERE]

\subsection{Insights from rainfall interception modelling}

556 We used a simplified version of the Rutter et al. (1971) model (described in Appendix C) at half-

557 hourly time step to simulate event-based rainfall interception losses for each site. We do not claim that

558 the derived estimates accurately reflect rainfall interception losses for individual sites, as we needed to

559 make assumptions about $S$ and about the canopy cover fraction. Rather, the objective of this exercise

560 was to further investigate the effect of assumed $S$ on simulated interception losses and to investigate

561 the order of magnitude of interception losses obtained when using our best estimate $\lambda E_{P M}$ values.

562 Figure 3 shows the relationship between assumed $S$ and the range of simulated values for interception

563 loss expressed as a percentage of rainfall. This shows that the estimated interception loss is sensitive

564 to the choice of $S$; interception loss increased approximately proportional to $S$ to the power 0.3 (Figure $5653)$.

[FIGURE 3 HERE]

569 Values of the minimum amount of water needed to saturate the canopy $(S)$ reported in the literature 570 are typically on the order of 0.5 to $2 \mathrm{~mm}$ (e.g., Wallace et al., 2013), but even within this range the 571 choice of value is quite influential. Interception loss estimates for this narrower $S$ range are in the 572 order of $10-50 \%$ with an average of ca. $20-30 \%$. These numbers are in fact surprisingly close to 
573 interception fractions observed by water budget methods. Of several vegetation and weather variables

574 tested, characteristics related to rainfall event size and intensity were the best predictors of

575 interception loss (in terms of $r^{2}$, data not shown), for any assumed value of $S$. Figure 4 illustrates this

576 using the average depth of rain per rain-day $\left(P_{d}\right.$, i.e. the ratio of annual rainfall over number of days

577 with rain, chosen because it is straightforward to calculate). The scatter in Figure 4 can be attributed

578 mainly to site-to-site variability in $E$ (hence the difference between short and tall vegetation) and to

579 differences in the temporal scaling behaviour of rainfall (e.g., the site US-Wrc represents tall

580 coniferous forest that experiences large storms in terms of total volume but falling with low $R$ ). The

581 lowest simulated interception loss was 4-26\% (range for different $S$ ) for a grassland in Mississippi,

582 USA (US-Goo), experiencing high $R$ (average $3.8 \mathrm{~mm} \mathrm{~h}^{-1}$ ) and average $E\left(0.10 \mathrm{~mm} \mathrm{~h}^{-1}\right)$ during

583 rainfall. The highest simulated interception loss was $27-59 \%$ for an evergreen forest in Italy (IT-Ren)

584 experiencing low $R\left(0.45 \mathrm{~mm} \mathrm{~h}^{-1}\right)$ and average $E\left(0.11 \mathrm{~mm} \mathrm{~h}^{-1}\right)$.

585

586 [FIGURE 4 HERE]

588 For $S=1 \mathrm{~mm}$, the resulting $R$ averaged over the entire event is considerably less than the $R$ calculated 589 for half hours with rainfall only (Table 4). This re-emphasises the point made earlier that event590 averaged $R$ will decrease when considering intra-storm periods without rain during which the canopy 591 does not fully dry (Valente et al., 1997). On the other hand, event-average $\bar{E}$ was not significantly 592 different from $E$ during rainfall intervals only (Table 4). The resulting ratios of mean $E$ over mean $R$ 593 were on average $2.05 \pm 0.63$ times greater than values calculated on the basis of half-hours with rainfall 594 only (range 1.13-4.20). Finally, $E$ during the drying out phase was considerably higher than that 595 during the event, by an average 2.02 \pm 0.69 times, although values varied considerably between sites 596 (range 0.61-4.64 times). The corresponding average drying time for $S=1 \mathrm{~mm}$ was simulated to be $597 \quad 3.9 \pm 1.9$ hours, but varied as a function of $E(1.2-12.2$ hours $)$.

[TABLE 4 HERE]

600

601 Incidentally, the best predictor of event-average $E$ was VPD $\left(r^{2}=0.53, N=82\right)$, whereas multiplying

602 VPD with $g_{a U}$ or $g_{a T}$ (cf. Eq. (1a)) further increased $r^{2}$ to 0.74 . This further emphasises the importance 603 of the aerodynamic term of $E_{P M}$. The contribution of the aerodynamic term in Eq. (1a) can also be 604 calculated directly and contributed an average $61 \pm 18 \%$ to total $E_{P M}$ during rainfall periods $(N=108)$.

605 As another aside, the model results presented here can also be used to examine one of the assumptions 606 of the analytical interception model, namely, that the ratio $\bar{E} / \bar{R}$ can be assumed constant over all 
607 events. Although this assumption can be argued against on conceptual grounds (greater storms might

608 be presumed to have greater rainfall rates), it generally does not appear to affect model performance

609 negatively. We examined the relationship between storm size $P(\mathrm{~mm})$ and $\bar{E} / \bar{R}$ for all individual sites

610 with more than 20 events in excess of $5 \mathrm{~mm}(N=74)$. For all but one site, $\bar{E} / \bar{R}$ in fact did decrease with

611 increasing storm size, but more so for small storms (e.g., $<5 \mathrm{~mm}$ ) than for larger ones. Overall,

612 correlation was typically not strong, with an average $r^{2}$ of $-0.23 \pm 0.08$. Further examination showed

613 that this was partly because $E$ slightly increased with increasing $P$, but mainly because $R$ was just not

614 strongly related to $P$. This explains why the assumption of constant $\bar{E} / \bar{R}$ often still produces good

615 agreement with canopy water budget observations.

616

\section{7. Conclusions}

618 In this study, we investigated why canopy water budget measurements of rainfall interception almost

619 always suggest wet canopy evaporation rates $\left(E_{W B}\right)$ that are several times higher than those predicted

620 from Penman-Monteith theory $\left(E_{P M}\right)$. We examined several proposed explanations for this

621 discrepancy by reviewing the literature and examining the FLUXNET database. We summarise our

622 main findings as follows:

623 [1] Relatively high $E$ can be sustained during rainfall by a combination of radiation, a downward

624 sensible heat flux, and heat release from the soil and canopy. Biomass heat release can be an

625 important source of energy for tall, dense forests experiencing a rapid drop in surface temperature due

626 to evaporative cooling. Accounting for it increased $E_{P M}$ for forest by $17 \%$. While lateral advection of

627 energy from nearby (dry) areas is plausible, large-scale lateral advection from a warmer ocean does

628 not need to be invoked to explain a downward heat flux. It is not obvious how the magnitude of the

629 downward heat flux during rainfall might be predicted, but it would likely require more explicit

630 consideration of boundary layer dynamics.

631 [2] The aerodynamic component of $E_{P M}$ is typically larger than the radiation component.

632 Correspondingly, $E_{P M}$ estimates are particularly sensitive to errors in air humidity and aerodynamic

633 conductance. Small measurement errors in air humidity are plausible and important: reducing

634 measured values by only $2 \% \mathrm{RH}$ increased $E_{P M}$ by an average $34 \%$. It follows that accurately

635 measuring RH may be particularly critical under wet conditions. Errors in the estimation of

636 aerodynamic conductance following conventional theory were large, but did not suggest a systematic 637 bias.

638 [3] FLUXNET eddy-covariance measurements of $E$ during rainfall were questionable. In addition,

639 rainfall is often associated with a downward heat flux, which promotes stable conditions and

640 supresses turbulence. Our results suggest that eddy-covariance flux measurement during rainfall

641 requires special scrutiny, and may require more flexible protocols for the analysis of raw high 
642 frequency data. Standard FLUXNET gap-filling procedures are not appropriate under these

643 conditions. Alternative latent heat flux estimates may be obtained from Penman-Monteith theory, but

644 this has its own uncertainties.

645 [4] In addition to the various reasons why $E_{P M}$ may be underestimated, applying rainfall interception

646 models to canopy water budget observations can also lead to overestimates of $E_{W B}$. In interpreting

647 event-based measurements, underestimation of canopy rainfall storage capacity $S$ and overestimation

648 of event-average rainfall rate $R$ can lead to overestimates of $E$ due to parameter equivalence within the

649 rainfall interception model. The impact of assumed canopy drying time needs to be considered

650 carefully when determining the number of storm events and their duration from rainfall rate

651 measurements.

652 [5] A Rutter-type time step rainfall interception model was applied with adjusted $E_{P M}$ estimates and

653 assumed vegetation properties. This produced hypothetical estimates that appeared to agree

654 surprisingly well with the magnitude of interception losses observed in field studies. Overall,

655 therefore, careful treatment and interpretation of observations may often already be sufficient to

656 reconcile canopy water budget measurements within a coupled water and energy balance framework.

657 Simultaneous measurements of rainfall, throughfall and meteorology within events are likely to be

658 helpful in this regard.

659 [6] Our limited understanding of boundary-layer dynamics during rainfall leaves important questions

660 unanswered. This includes the controls on the downward heat flux, local horizontal advection,

661 infrequent large-scale turbulence, possible upwards transport of small splash droplets, and the

662 influence of rainfall recycling on rainfall generation downwind. These uncertainties can have

663 important implications for coupled land surface - atmosphere modelling as well as water management,

664 and therefore merit further study. 
667 A.v.D. designed the methodology based on discussion with J.G., performed the analysis and wrote the 668 first draft. J.G. and E.v.G. suggested major improvements to the argument and structure of the first 669 draft. The other authors offered improvements to later manuscript versions.

670

671 This work used eddy-covariance data acquired by the FLUXNET community and in particular by the

672 following networks: AmeriFlux (U.S. Department of Energy, Biological and Environmental Research,

673 Terrestrial Carbon Program (DE-FG02-04ER63917 and DE-FG02-04ER63911), AfriFlux, AsiaFlux,

674 CarboAfrica, CarboEuropeIP, CarboItaly, CarboMont, ChinaFlux, Fluxnet-Canada (supported by

675 CFCAS, NSERC, BIOCAP, Environment Canada, and NRCan), GreenGrass, KoFlux, LBA, NECC,

676 OzFlux, TCOS-Siberia, USCCC. We acknowledge the financial support to the eddy-covariance data

677 harmonization provided by CarboEuropeIP, FAO-GTOS-TCO, iLEAPS, Max Planck Institute for

678 Biogeochemistry, National Science Foundation, University of Tuscia, Université Laval, Environment

679 Canada and US Department of Energy and the database development and technical support from

680 Berkeley Water Center, Lawrence Berkeley National Laboratory, Microsoft Research eScience, Oak

681 Ridge National Laboratory, University of California - Berkeley and the University of Virginia. We

682 thank Dr Beverly Law and other FLUXNET members for allowing the use of their data, and for their

683 encouragement and useful suggestions along the way. We also thank an anonymous referee and Dr

684 David Fitzjarrald for their constructive reviews.

685

686

687 
688 Appendix A. FLUXNET sites used in the analysis

689 We used only original (i.e. not gap-filled) half-hourly data. For each analysis we only included sites

690 with the equivalent of more than a year of data that included observations during rainfall. The 128

691 FLUXNET sites with the following codes were used in some or all of the energy balance and latent

692 heat flux analyses and/or interception modelling (primary reference between brackets, where

693 available):

694 AT-Neu (Wohlfahrt et al., 2008), AU-Fog, AU-How (Beringer et al., 2011), AU-Tum (Leuning et al., 695 2005), AU-Wac (Kilinc et al., 2012), BE-Bra, BE-Lon, BE-Vie, BW-Ma1, CA-Ca1 (Brümmer et al.,

696 2012), CA-Ca2 (Jassal et al., 2009), CA-Ca3 (Humphreys et al., 2006), CA-Gro (McCaughey et al., 697 2006), CA-Let (Flanagan and Adkinson, 2011), CA-Man (Dunn et al., 2007), CA-Mer (Lafleur et al., 698 2003), CA-Oas (Zha et al., 2010), CA-Obs (Krishnan et al., 2008), CA-Ojp (Kljun et al., 2006), CA699 Qcu (Giasson et al., 2006), CA-Qfo (Bergeron et al., 2007), CA-SF1, -SF2 and -SF3 (Mkhabela et al., 700 2009), CA-TP4 (Arain and Restrepo-Coupe, 2005), CH-Oe1 (Ammann et al., 2007), CN-Du1 and 701 Du2 (Yan et al., 2008), CN-HaM, CN-Xfs, CN-Xi2, CZ-BK1, DE-Bay (Staudt and Foken, 2007), DE702 Geb, DE-Gri, DE-Hai (Knohl et al., 2003), DE-Har, DE-Meh, DE-Tha, DE-Wet, DK-Sor (Pilegaard 703 et al., 2011), ES-ES1, ES-VDA, FI-Hyy, FI-Kaa, FI-Sod, FR-Gri (Loubet et al., 2011), FR-Hes, FR704 LBr (Berbigier et al., 2001), FR-Lq1, FR-Lq2, FR-Pue, HU-Bug (Nagy et al., 2007), HU-Mat (Pintér 705 et al., 2010), IE-Ca1, IE-Dri (Peichl et al., 2011), IL-Yat (Rotenberg and Yakir, 2010), IS-Gun, IT706 Amp, IT-BCi, IT-Col, IT-Cpz (Garbulsky et al., 2008), IT-Lav, IT-MBo (Marcolla et al., 2011), IT707 Mal, IT-Non, IT-PT1 (Migliavacca et al., 2009), IT-Ren (Montagnani et al., 2009), IT-Ro1 (Rey et al., 708 2002), IT-Ro2 (Tedeschi et al., 2006), IT-SRo, JP-Mas, JP-Tom, KR-Hnm, NL-Ca1 (Jacobs et al., 709 2007), NL-Hor (Hendriks et al., 2007), NL-Loo (Moors, 2012), PT-Mi2 (Pereira et al., 2007), RU-Fyo 710 (Milyukova et al., 2002), RU-Zot, SE-Faj (Lund et al., 2007), SE-Fla (Lindroth et al., 2008), SE-Nor 711 (Lindroth et al., 1998), UK-ESa, UK-Gri, UK-Ham, US-ARM, US-Atq, US-Aud, US-Bkg, US-Blo, 712 US-Bo1, US-Bo2, US-Brw, US-CaV, US-Dk1, US-Dk3, US-FPe, US-Goo, US-Ha1 (Urbanski et al., 713 2007), US-Ho1, US-IB1, US-IB2, US-Ivo, US-KS2, US-MMS, US-MOz, US-Me2 (Thomas et al., 714 2009), US-NC1 (Noormets et al., 2012), US-NC2 (Noormets et al., 2010), US-NR1, US-Ne1, US715 Ne2, US-Ne3, US-SO2, US-SO3, US-SO4, US-SP2, US-SP3, US-SRM (Scott et al., 2009), US-Syv, 716 US-Ton (Ma et al., 2007), US-UMB (Maurer et al., 2013), US-Var (Ma et al., 2007), US-WCr, US717 Wi4 (Noormets et al., 2007), US-Wkg (Scott et al., 2010), and US-Wrc. 


\section{Appendix B. Canopy heat flux estimation}

721 Michiles and Gielow (2008) found that the following approximation produced good results for $Q_{a}$ (cf.

722 McCaughey, 1985):

$723 \quad Q_{a}=\rho\left(c_{p} \Delta \bar{T}+\lambda \Delta \bar{q}\right) \frac{\Delta z}{\Delta t}$

724 where $\Delta \bar{T}(\mathrm{~K})$ and $\Delta \bar{q}\left(\mathrm{~kg} \mathrm{~kg}^{-1}\right)$ are the change in mean air temperature and specific humidity,

725 respectively, $\Delta z(\mathrm{~m})$ the height of the air column considered and $\Delta t(\mathrm{~s})$ the time between two

726 measurements. A similar equation describes $Q_{v}$ (McCaughey, 1985; Oliphant et al., 2004; Thom,

727 1975; Wilson and Baldocchi, 2000):

$728 \quad Q_{v}=m_{v} c_{v} \frac{\Delta T_{v}}{\Delta t}$

729 where $m_{v}\left(\mathrm{~kg} \mathrm{~m}^{-2}\right)$ is the amount of fresh biomass per unit area, $c_{v}\left(\mathrm{~J} \mathrm{~kg}^{-1} \mathrm{~K}^{-1}\right)$ the average specific

730 heat, and $\Delta T_{\mathrm{v}}(\mathrm{K})$ the average change in biomass temperature. An unknown variable in this study is

$731 T_{v}$, given the lagged temperature changes in bulky biomass elements such as trunks and branches (e.g.,

732 Lindroth et al., 2010; Oliphant et al., 2004). Gradient methods have been developed to estimate heat

733 storage changes in tree trunks (Meesters and Vugts, 1996) but require detailed information on the

734 vegetation and hence were not feasible here. Alternatively, Michiles and Gielow (2008) proposed an

735 approach that empirically estimates biomass temperature as a delayed and attenuated function of air

736 temperature. However, it is not clear if this empirical function, developed for dry and wet, and day

737 and night periods alike, is suitable during rainfall, when biomass surface cooling may be rapid.

738 Instead, as a first approximation, we estimated the magnitude of biomass heat flux by applying Eq

739 (B.2) assuming that $T_{v}$ equals air temperature for intervals without rainfall, and wet bulb temperature

740 for intervals with rainfall calculated following Stull (2011). Failure to account for the gradual release

741 of heat may lead to overestimation of biomass heat release during the early stages of a storm, but it

742 will to some extent be compensated by corresponding underestimation during later stages of the

743 storm. On the other hand, biomass temperature before the storm may exceed air temperature, in which

744 case the energy available for release will be underestimated. For $c_{v}$, values of $2466-3340 \mathrm{~J} \mathrm{~kg}^{-1} \mathrm{~K}^{-1}$

745 have been reported (Michiles and Gielow, 2008; Oliphant et al., 2004). We did not have detailed heat

746 capacity or biomass data for each site, and therefore had to make assumptions. For an Amazonian

747 forest, Michiles and Gielow (2008) estimated a total heat capacity of $70450 \mathrm{~J} \mathrm{~m}^{-2} \mathrm{~K}^{-1}$. Dividing this by

748 the forest height $(23.5 \mathrm{~m})$ suggests a biomass heat capacity per unit forest volume (i.e., biomass plus

749 air) of $2998 \mathrm{~J} \mathrm{~m}^{-3} \mathrm{~K}^{-1}$. Applying the same calculation to data presented by Kilinc et al. (2012) for an

$75080 \mathrm{~m}$ Australian mountain ash forest suggests a heat capacity of $3939 \mathrm{~J} \mathrm{~m}^{-3} \mathrm{~K}^{-1}$. Based on these

751 numbers, we estimated the product $m_{v} c_{v}$ as $3500 \mathrm{~J} \mathrm{~m}^{-2} \mathrm{~K}^{-1}$ per metre vegetation height. Values for 
752 these were sourced from publications or the web sites of FLUXNET and its contributing regional 753 networks.

754

755 
We applied the Rutter et al. (1971) rainfall interception model with four simplifying assumptions: (1) the canopy has full cover; (2) drainage of water in excess of rainfall storage capacity occurs sufficiently rapidly and therefore its influence on interception losses can be ignored at half-hourly time step, (3) the trunks behave as an integral part of the vegetation and therefore their water balance does not need to be considered separately, and (4) wet canopy evaporation is limited by the amount of water on the canopy surface ( $C$ in $\mathrm{mm}$ ), but does not linearly scale with it. With these assumptions $C(t)$ at the end of period $t$ is predicted as (Rutter et al., 1971; Rutter, 1975):

with limitations $C(t) \leq S$ and $E^{\prime}(t) \leq C(t-1)+P^{\prime}(t)$, where $P^{\prime}$ and $E^{\prime}$ are rainfall and total wet canopy evaporation (mm) during time interval $t . E^{\prime}$ was estimated from $\lambda E_{P M}$ and missing values during and after rainfall were estimated as the mean $\lambda E_{P M}$ for all time intervals with and without rainfall, respectively. Different values of $S$ between 0.1 and $5 \mathrm{~mm}$ were tested, covering a realistic range of values reported in the literature. A brief discussion of the simplifying assumptions follows.

- Assumption (1) was made to avoid mathematical inconsistencies in the model and to keep the model simple, rather than resort to partial canopy models, which require more assumptions and input data and are more cumbersome to interpret (Gash et al., 1995; Valente et al., 1997; Van Dijk and Bruijnzeel, 2001a). Canopy cover is close to unity for many of the FLUXNET sites and for those cases the impact will be minor. However, for sites with partial or seasonally varying canopy cover (e.g. open forests, crop sites) the resulting interception estimates should be considered unrealistic.

- Assumption (2) will have little influence on the results, as the rate of drainage is normally high and because rainfall storage in excess of $S$ does not lead to greater $E$ in the original model (Rutter et al., 1971). It is also consistent with the derivation of the event-based model by Gash (1979),

- Assumption (4) is potentially more influential. In the original model formulation $E$ scales linearly who assumed that drainage from the saturated canopy would become negligible within 20 to 30 min after the end of a storm.

- Assumption (3) has a sound conceptual basis but in any case will also not substantially affect the simulated interception losses as the stemflow fraction is normally very small (Van Dijk and Bruijnzeel, 2001a; Wallace et al., 2013).

with the ratio $C / S$. We did not adhere to this formulation because it would prevent the canopy from ever drying completely between storms. Moreover there is in fact little empirical support to suggest that wet canopy evaporation is linearly proportional to rainfall storage on the canopy (but see Shuttleworth, 1976; Shuttleworth, 1977). It is noted that this assumption has no effect when $R$ 

assumption, the model was also applied in its original form. This produced interception estimates that were only $4-5 \%$ smaller and the values were highly correlated $\left(r^{2}>0.99\right)$ with values of $S$. 


\section{References}

Amiro, B.D. et al., 2006. Carbon, energy and water fluxes at mature and disturbed forest sites, Saskatchewan, Canada. Agricultural and Forest Meteorology, 136(3-4): 237-251.

Ammann, C., Flechard, C., Leifeld, J., Neftel, A. and Fuhrer, J., 2007. The carbon budget of newly established temperate grassland depends on management intensity. Agriculture, ecosystems \& environment, 121(1): 5-20.

Arain, M.A. and Restrepo-Coupe, N., 2005. Net ecosystem production in a temperate pine plantation in southeastern Canada. Agricultural and Forest Meteorology, 128(3-4): 223-241.

Aubinet, M., Vesala, T. and Papale, D., 2012. Eddy covariance: a practical guide to measurement and data analysis. Springer.

Baldocchi, D., 2008. Turner Review No. 15: 'Breathing' of the terrestrial biosphere: lessons learned from a global network of carbon dioxide flux measurement systems. Australian Journal of Botany, 56(1): 26.

Baldocchi, D. et al., 2001. FLUXNET: A New Tool to Study the Temporal and Spatial Variability of Ecosystem-Scale Carbon Dioxide, Water Vapor, and Energy Flux Densities. Bulletin of the American Meteorological Society, 82(11): 2415-2434.

Bassette, C. and Bussière, F., 2008. Partitioning of splash and storage during raindrop impacts on banana leaves. Agricultural and Forest Meteorology, 148(6): 991-1004.

Belcher, S. E., Finnigan, J. J., and Harman, I. N., 2008. Flows through forest canopies in complex terrain. Ecological Appliactions, 18: 1436-1453.

Belcher, S. E., Harman, I. N., and Finnigan, J. J., 2012. The wind in the willows: Flows in forest canopies in complex terrain. Annual Review of Fluid Mechanics, 44: 479-504.

Berbigier, P., Bonnefond, J.-M. and Mellmann, P., 2001. $\mathrm{CO}_{2}$ and water vapour fluxes for 2 years above Euroflux forest site. Agricultural and Forest Meteorology, 108(3): 183-197.

Bergeron, O. et al., 2007. Comparison of carbon dioxide fluxes over three boreal black spruce forests in Canada. Global Change Biology, 13(1): 89-107.

Beringer, J. et al., 2011. SPECIAL—Savanna Patterns of Energy and Carbon Integrated across the Landscape. Bulletin of the American Meteorological Society, 92(11): 1467-1485.

Beven, K., 1993. Prophecy, reality and uncertainty in distributed hydrological modelling. Advances in Water Resources, 16: 41-41.

Blyth, E.M., Dolman, A.J. and Noilhan, J., 1994. The efect of forest on mesoscale rainfall: an example from HAPEX-MOBILHY. Journal of Applied Meteorology, 33(4): 445-454.

Bonan, G.B., 2008. Forests and Climate Change: Forcings, Feedbacks, and the Climate Benefits of Forests. Science, 320(5882): 1444-1449. 
Brümmer, C. et al., 2012. How climate and vegetation type influence evapotranspiration and water use efficiency in Canadian forest, peatland and grassland ecosystems. Agricultural and Forest Meteorology, 153: 14-30.

Burba, G.G., McDermitt, D.K., Anderson, D.J., Furtaw, M.D. and Eckles, R.D., 2010. Novel design of an enclosed $\mathrm{CO}_{2} / \mathrm{H}_{2} \mathrm{O}$ gas analyser for eddy covariance flux measurements. Tellus $\mathrm{B}$, 62(5): 743-748.

Cabral, O.M.R. et al., 2010. The energy and water balance of a Eucalyptus plantation in southeast Brazil. Journal of Hydrology, 388(3-4): 208-216.

Chen, S. et al., 2009. Energy balance and partition in Inner Mongolia steppe ecosystems with different land use types. Agricultural and Forest Meteorology, 149(11): 1800-1809.

Crockford, R.H. and Richardson, D.P., 2000. Partitioning of rainfall into throughfall, stemflow and interception: effect of forest type, ground cover and climate. Hydrological Processes, 14(1617): 2903-2920.

Curtis, P.S. et al., 2002. Biometric and eddy-covariance based estimates of annual carbon storage in five eastern North American deciduous forests. Agricultural and Forest Meteorology, 113(14): 3-19.

Czikowsky, M.J. and Fitzjarrald, D.R., 2009. Detecting rainfall interception in an Amazonian rain forest with eddy flux measurements. Journal of Hydrology, 377(1-2): 92-105.

Dunin, F., O'Loughlin, E. and Reyenga, W., 1988. Interception loss from eucalypt forest: lysimeter determination of hourly rates for long term evaluation. Hydrological Processes, 2(4): 315329.

Dunkerley, D.L., 2009. Evaporation of impact water droplets in interception processes: Historical precedence of the hypothesis and a brief literature overview. Journal of Hydrology, 376(3): 599-604.

Dunn, A.L., Barford, C.C., Wofsy, S.C., Goulden, M.L. and Daube, B.C., 2007. A long-term record of carbon exchange in a boreal black spruce forest: means, responses to interannual variability, and decadal trends. Global Change Biology, 13(3): 577-590.

Finnigan, J.J., Clement, R., Malhi, Y., Leuning, R. and Cleugh, H.A., 2003. A Re-Evaluation of Long-Term Flux Measurement Techniques Part I: Averaging and Coordinate Rotation. Boundary-Layer Meteorology, 107(1): 1-48.

Finnigan, J.J., 2004. Advection and modelling. In: Lee, X., Massman, W., Law, B. (Eds.), Handbook of Micrometeorology: A Guide for Surface Flux Measurements, Kluwer Academic Publishers, p. 209-241.

Flanagan, L.B. and Adkinson, A.C., 2011. Interacting controls on productivity in a northern Great Plains grassland and implications for response to ENSO events. Global Change Biology, 17(11): 3293-3311. 
Foken, T., 2008. The energy balance closure problem: an overview. Ecological Applications, 18(6): 1351-1367.

Fratini, G., Ibrom, A., Arriga, N., Burba, G. and Papale, D., 2012. Relative humidity effects on water vapour fluxes measured with closed-path eddy-covariance systems with short sampling lines. Agricultural and Forest Meteorology, 165(0): 53-63.

Garbulsky, M.F., Peñuelas, J., Papale, D. and Filella, I., 2008. Remote estimation of carbon dioxide uptake by a Mediterranean forest. Global Change Biology, 14(12): 2860-2867.

Gash, J.H.C., 1979. An analytical model of rainfall interception by forests. Quarterly Journal of the Royal Meteorological Society, 105: 43-55.

Gash, J.H.C., Lloyd, C.R. and Lachaud, G., 1995. Estimating sparse forest rainfall interception with an analytical model. Journal of Hydrology, 170(1-4): 79-86.

Gash, J.H.C. and Shuttleworth, W.J. (Editors), 2007. Evaporation. Benchmark papers in hydrology, 2, $521 \mathrm{pp}$.

Gash, J.H.C., Valente, F. and David, J.S., 1999. Estimates and measurements of evaporation from wet, sparse pine forest in Portugal. Agricultural and Forest Meteorology, 94(2): 149-158.

Ghadiri, H. and Payne, D., 1988. The formation and characteristics of splash following raindrop impact on soil. Journal of Soil Science, 39(4): 563-575.

Giasson, M.-A., Coursolle, C. and Margolis, H.A., 2006. Ecosystem-level $\mathrm{CO}_{2}$ fluxes from a boreal cutover in eastern Canada before and after scarification. Agricultural and Forest Meteorology, 140(1-4): 23-40.

Guerschman, J.P. et al., 2009. Scaling of potential evapotranspiration with MODIS data reproduces flux observations and catchment water balance observations across Australia. Journal of Hydrology, 369(1-2): 107-119.

Gunn, R. and Kinzer, G.D., 1949. The terminal velocity of fall for water droplets on stagnant air. Journal of Meteorology, 6(4): 243-248.

Harman, I. N., Finnigan, J. J., 2008. Scalar concentration profiles in the canopy and roughness sublayer. Boundary-Layer Meteorology, 129(3):323-351.

Haverd, V., Cuntz, M., Leuning, R. and Keith, H., 2007. Air and biomass heat storage fluxes in a forest canopy: calculation within a soil vegetation atmosphere transfer model. Agricultural and forest meteorology, 147(3): 125-139.

Hendriks, D.M.D., van Huissteden, J., Dolman, A.J. and van der Molen, M.K., 2007. The full greenhouse gas balance of an abandoned peat meadow. Biogeosciences, 4(3): 411-424.

Herbst, M., Rosier, P.T., McNeil, D.D., Harding, R.J. and Gowing, D.J., 2008. Seasonal variability of interception evaporation from the canopy of a mixed deciduous forest. Agricultural and forest meteorology, 148(11): 1655-1667.

Herwitz, S.R., 1985. Interception storage capacities of tropical rainforest canopy trees. Journal of Hydrology, 77(1): 237-252. 
Hölscher, D., Kohler, L., van Dijk, A. and Bruijnzeel, L., 2004. The importance of epiphytes to total rainfall interception by a tropical montane rain forest in Costa Rica. Journal of Hydrology, 292(1-4): 308-322.

Holwerda, F., Bruijnzeel, L., Scatena, F., Vugts, H. and Meesters, A., 2012. Wet canopy evaporation from a Puerto Rican lower montane rain forest: The importance of realistically estimated aerodynamic conductance. Journal of Hydrology, 414: 1-15.

Holwerda, F., Scatena, F. and Bruijnzeel, L., 2006. Throughfall in a Puerto Rican lower montane rain forest: a comparison of sampling strategies. Journal of Hydrology, 327(3): 592-602.

Horton, R.E., 1919. Rainfall interception. Monthly Weather Review, 47(9): 603-623.

Humphreys, E.R. et al., 2006. Carbon dioxide fluxes in coastal Douglas-fir stands at different stages of development after clearcut harvesting. Agricultural and Forest Meteorology, 140(1): 6-22.

Huntingford, C., Blyth, E.M., Wood, N., Hewe, F.E., Grant, A., 1998. The effect of topopgraphy on evaporation. Boundary-Layer Meteorology, 86(3): 487-504.

Ibrom, A., Dellwik, E., Flyvbjerg, H., Jensen, N.O. and Pilegaard, K., 2007. Strong low-pass filtering effects on water vapour flux measurements with closed-path eddy correlation systems. Agricultural and Forest Meteorology, 147(3-4): 140-156.

Jacobs, C.M.J. et al., 2007. Variability of annual $\mathrm{CO}_{2}$ exchange from Dutch grasslands. Biogeosciences, 4(5): 803-816.

Jassal, R.S., Black, T.A., Spittlehouse, D.L., Brümmer, C. and Nesic, Z., 2009. Evapotranspiration and water use efficiency in different-aged Pacific Northwest Douglas-fir stands. Agricultural and Forest Meteorology, 149(6): 1168-1178.

Kilinc, M., Beringer, J., Hutley, L.B., Haverd, V. and Tapper, N., 2012. An analysis of the surface energy budget above the world's tallest angiosperm forest. Agricultural and Forest Meteorology, 166: 23-31.

Kljun, N. et al., 2006. Response of net ecosystem productivity of three boreal forest stands to drought. Ecosystems, 9(7): 1128-1144.

Knohl, A., Schulze, E.-D., Kolle, O. and Buchmann, N., 2003. Large carbon uptake by an unmanaged 250-year-old deciduous forest in Central Germany. Agricultural and Forest Meteorology, 118(3): 151-167.

Kobayashi, H. et al., 2012. Modeling energy and carbon fluxes in a heterogeneous oak woodland: A three-dimensional approach. Agricultural and Forest Meteorology, 152(0): 83-100.

Krishnan, P. et al., 2008. Factors controlling the interannual variability in the carbon balance of a southern boreal black spruce forest. Journal of Geophysical Research: Atmospheres (19842012), 113(D9).

Lafleur, P.M., Roulet, N.T., Bubier, J.L., Frolking, S. and Moore, T.R., 2003. Interannual variability in the peatland-atmosphere carbon dioxide exchange at an ombrotrophic bog. Global Biogeochemical Cycles, 17(2): 1036. 
Law, F., 1957. Measurement of rainfall, interception and evaporation losses in a plantation of Sitka spruce trees. IAHS Publication no, 44: 397-411.

Leuning, R., Cleugh, H.A., Zegelin, S.J. and Hughes, D., 2005. Carbon and water fluxes over a temperate Eucalyptus forest and a tropical wet/dry savanna in Australia: measurements and comparison with MODIS remote sensing estimates. Agricultural and Forest Meteorology, 129(3-4): 151-173.

Levia, D.F. and Frost, E.E., 2003. A review and evaluation of stemflow literature in the hydrologic and biogeochemical cycles of forested and agricultural ecosystems. Journal of Hydrology, 274(1-4): 1-29.

Leyton, L., Reynolds, E.R.C. and Thompson, F.B., 1967. Rainfall interception in forest and moorland. In: W.E. Sopper and H.W. Lull (Editors), Forest Hydrology. Pergamon, New York, NY, pp. 163-178.

Lindroth, A., Grelle, A. and Morén, A.-S., 1998. Long-term measurements of boreal forest carbon balance reveal large temperature sensitivity. Global Change Biology, 4(4): 443-450.

Lindroth, A., Klemedtsson, L., Grelle, A., Weslien, P. and Langvall, O., 2008. Measurement of net ecosystem exchange, productivity and respiration in three spruce forests in Sweden shows unexpectedly large soil carbon losses. Biogeochemistry, 89(1): 43-60.

Lindroth, A., Mölder, M. and Lagergren, F., 2010. Heat storage in forest biomass improves energy balance closure. Biogeosciences, 7(1): 301-313.

Llorens, P. and Domingo, F., 2007. Rainfall partitioning by vegetation under Mediterranean conditions. A review of studies in Europe. Journal of Hydrology, 335(1-2): 37-54.

Lloyd, C.R. and Marques, A., 1988. Spatial variability of throughfall and stemflow measurements in Amazonian rainforest. Agricultural and Forest Meteorology, 42(1): 63-73.

Loubet, B. et al., 2011. Carbon, nitrogen and Greenhouse gases budgets over a four years crop rotation in northern France. Plant and Soil, 343(1-2): 109-137.

Lund, M., Lindroth, A., Christensen, T.R. and Ström, L., 2007. Annual $\mathrm{CO}_{2}$ balance of a temperate bog. Tellus B, 59(5): 804-811.

Ma, S., Baldocchi, D.D., Xu, L. and Hehn, T., 2007. Inter-annual variability in carbon dioxide exchange of an oak/grass savanna and open grassland in California. Agricultural and Forest Meteorology, 147(3): 157-171.

Marcolla, B. et al., 2011. Climatic controls and ecosystem responses drive the inter-annual variability of the net ecosystem exchange of an alpine meadow. Agricultural and Forest Meteorology 151(9): 1233-1243.

Mammarella, I. et al., 2009. Relative Humidity Effect on the High-Frequency Attenuation of Water Vapor Flux Measured by a Closed-Path Eddy Covariance System. Journal of Atmospheric and Oceanic Technology, 26(9): 1856-1866. 
Maurer, K.D., Hardiman, B.S., Vogel, C.S. and Bohrer, G., 2013. Canopy-structure effects on surface roughness parameters: Observations in a Great Lakes mixed-deciduous forest. Agricultural and Forest Meteorology, 177(0): 24-34.

McCaughey, J., 1985. Energy balance storage terms in a mature mixed forest at Petawawa, Ontarioa case study. Boundary-Layer Meteorology, 31(1): 89-101.

McCaughey, J., Pejam, M., Arain, M. and Cameron, D., 2006. Carbon dioxide and energy fluxes from a boreal mixedwood forest ecosystem in Ontario, Canada. Agricultural and Forest Meteorology, 140(1): 79-96.

Meesters, A. and Vugts, H., 1996. Calculation of heat storage in stems. Agricultural and Forest Meteorology, 78(3): 181-202.

Michiles, A.A.d.S. and Gielow, R., 2008. Above-ground thermal energy storage rates, trunk heat fluxes and surface energy balance in a central Amazonian rainforest. Agricultural and Forest Meteorology, 148(6-7): 917-930.

Migliavacca, M. et al., 2009. Seasonal and interannual patterns of carbon and water fluxes of a poplar plantation under peculiar eco-climatic conditions. Agricultural and Forest Meteorology, 149(9): 1460-1476.

Milyukova, I.M. et al., 2002. Carbon balance of a southern taiga spruce stand in European Russia. Tellus B, 54(5): 429-442.

Miralles, D.G., Gash, J.H., Holmes, T.R.H., de Jeu, R.A.M. and Dolman, A., 2010. Global canopy interception from satellite observations. Journal of Geophysical Research, 115(D16): D16122.

Mizutani, K., Yamanoi, K., Ikeda, T. and Watanabe, T., 1997. Applicability of the eddy correlation method to measure sensible heat transfer to forest under rainfall conditions. Agricultural and forest meteorology, 86(3): 193-203.

Mkhabela, M.S. et al., 2009. Comparison of carbon dynamics and water use efficiency following fire and harvesting in Canadian boreal forests. Agricultural and Forest Meteorology, 149(5): 783794.

Moffat, A.M. et al., 2007. Comprehensive comparison of gap-filling techniques for eddy covariance net carbon fluxes. Agricultural and Forest Meteorology, 147(3-4): 209-232.

Montagnani, L. et al., 2009. A new mass conservation approach to the study of $\mathrm{CO}_{2}$ advection in an alpine forest. Journal of Geophysical Research: Atmospheres (1984-2012), 114(D7).

Monteith, J.L., 1981. Evaporation and surface temperature. Quarterly Journal of the Royal Meteorological Society, 107(451): 1-27.

Moors, E.J., 2012. Water use of forests in the Netherlands. PhD Thesis,. VU University Amsterdam, Amsterdam.

Murakami, S., 2006. A proposal for a new forest canopy interception mechanism: Splash droplet evaporation. Journal of Hydrology, 319(1-4): 72-82. 
Muzylo, A. et al., 2009. A review of rainfall interception modelling. Journal of Hydrology, 370(1-4): 191-206.

Nagy, Z. et al., 2007. The carbon budget of semi-arid grassland in a wet and a dry year in Hungary. Agriculture, ecosystems \& environment, 121(1): 21-29.

Noormets, A., Chen, J. and Crow, T., 2007. Age-Dependent Changes in Ecosystem Carbon Fluxes in Managed Forests in Northern Wisconsin, USA. Ecosystems, 10(2): 187-203.

Noormets, A. et al., 2010. Response of carbon fluxes to drought in a coastal plain loblolly pine forest. Global Change Biology, 16(1): 272-287.

Noormets, A. et al., 2012. The role of harvest residue in rotation cycle carbon balance in loblolly pine plantations. Respiration partitioning approach. Global Change Biology, 18(10): 3186-3201.

Oliphant, A. et al., 2004. Heat storage and energy balance fluxes for a temperate deciduous forest. Agricultural and Forest Meteorology, 126(3): 185-201.

Paulson, C.A., 1970. The mathematical representation of wind speed and temperature profiles in the unstable atmospheric surface layer. Journal of Applied Meteorology, 9(6): 857-861.

Peichl, M., Leahy, P. and Kiely, G., 2011. Six-year Stable Annual Uptake of Carbon Dioxide in Intensively Managed Humid Temperate Grassland. Ecosystems, 14(1): 112-126.

Penman, H., 1952. The physical bases of irrigation control, 13th International hort. Congress. London.

Pereira, F., Gash, J., David, J. and Valente, F., 2009. Evaporation of intercepted rainfall from isolated evergreen oak trees: Do the crowns behave as wet bulbs? Agricultural and Forest Meteorology, 149(3): 667-679.

Pereira, J.S. et al., 2007. Net ecosystem carbon exchange in three contrasting Mediterranean ecosystems \&ndash; the effect of drought. Biogeosciences, 4(5): 791-802.

Pilegaard, K., Ibrom, A., Courtney, M.S., Hummelshøj, P. and Jensen, N.O., 2011. Increasing net $\mathrm{CO}_{2}$ uptake by a Danish beech forest during the period from 1996 to 2009. Agricultural and Forest Meteorology, 151(7): 934-946.

Pintér, K., Balogh, J. and Nagy, Z., 2010. Ecosystem scale carbon dioxide balance of two grasslands in Hungary under different weather conditions. Acta Biologica Hungarica, 61: 130-135.

Raupach, M.R., Weng, W.S., Carruthers, D.J., Hunt, J.C.R., 1992. Temperature and humidity fields and fluxes over low hills. Quarterly Journal of the Royal Meteorological Society 118(504), 191-225.

Raupach, M. R., Finnigan, J. J., and Brunet, Y., 1996. Coherent eddies and turbulence in vegetation canopies: the mixing length analogy. Boundary-Layer Meteorology, 78:351-382.

Raupach, M.R., Finnigan, J.J., 1997. The influence of topography on meteorology variables and surface-atmosphere interactions. Journal of Hydrology, 190, 182-213.

Rebmann, C. et al., 2005. Quality analysis applied on eddy covariance measurements at complex forest sites using footprint modelling. Theoretical and Applied Climatology, 80(2-4): 121141. 
1046

1047

1048

1049

1050

1051

1052

1053

1054

1055

1056

1057

1058

1059

1060

1061

1062

1063

1064

1065

1066

1067

1068

1069

1070

1071

1072

1073

1074

1075

1076

1077

1078

1079

1080

1081

Rey, A. et al., 2002. Annual variation in soil respiration and its components in a coppice oak forest in Central Italy. Global Change Biology, 8(9): 851-866.

Richardson, A.D. et al., 2006. A multi-site analysis of random error in tower-based measurements of carbon and energy fluxes. Agricultural and Forest Meteorology, 136(1-2): 1-18.

Roberts, J., 1999. Plants and water in forests and woodlands, Ecohydrology. Routledge, London, UK.

Roberts, J.M., Gash, J.H.C., Tani, M. and Bruijnzeel, L.A., 2005. Controls on evaporation in lowland tropical rainforest. In: M. Bonell and L.A. Bruijnzeel (Editors), Forests, Water and People in the Humid Tropics: Past, Present and Future Hydrological Research for Integrated Land and Water Management. Cambridge University Press, Cambridge, pp. 287-313.

Ross, A.N., 2011. Scalar transport over forested hills. Boundary-Layer Meteorology, 141:179-199.

Rotenberg, E. and Yakir, D., 2010. Contribution of Semi-Arid Forests to the Climate System. Science, 327(5964): 451-454.

Rutter, A., Kershaw, K., Robins, P. and Morton, A., 1971. A predictive model of rainfall interception in forests, 1. Derivation of the model from observations in a plantation of Corsican pine. Agricultural Meteorology, 9: 367-384.

Rutter, A.J. (Editor), 1967. An analysis of evaporation from a stand of Scots pine. International Symposium on Forest Hydrology. Pergamon Press, Oxford, UK, 403-416 pp.

Rutter, A.J., 1975. The hydrological cycle in vegetation. In: J.L. Monteith (Editor), Vegetation and the atmosphere: Volume 1, Principles. Academic Press: London, pp. 111-154.

Sakai, R.K., Fitzjarrald, D.R. and Moore, K.E., 2001. Importance of Low-Frequency Contributions to Eddy Fluxes Observed over Rough Surfaces. Journal of Applied Meteorology, 40(12): 21782192.

Schellekens, J., Scatena, F.N., Bruijnzeel, L.A. and Wickel, A.J., 1999. Modelling rainfall interception by a lowland tropical rain forest in northeastern Puerto Rico. Journal of Hydrology, 225(3-4): 168-184.

Schmidt, A., Hanson, C., Chan, W.S. and Law, B.E., 2012. Empirical assessment of uncertainties of meteorological parameters and turbulent fluxes in the AmeriFlux network. Journal of Geophysical Research: Biogeosciences, 117(G4): G04014.

Scott, R.L., Hamerlynck, E.P., Jenerette, G.D., Moran, M.S. and Barron-Gafford, G.A., 2010. Carbon dioxide exchange in a semidesert grassland through drought-induced vegetation change. Journal of Geophysical Research: Biogeosciences (2005-2012), 115(G3).

Scott, R.L., Jenerette, G.D., Potts, D.L. and Huxman, T.E., 2009. Effects of seasonal drought on net carbon dioxide exchange from a woody-plant-encroached semiarid grassland. Journal of Geophysical Research: Biogeosciences (2005-2012), 114(G4).

Sevruk, B., 2006. Rainfall Measurement: Gauges, Encyclopedia of Hydrological Sciences. John Wiley \& Sons, Ltd. 
1082

1083

1084

1085

1086

1087

1088

1089

1090

1091

1092

1093

1094

1095

1096

1097

1098

1099

1100

1101

1102

1103

1104

1105

1106

1107

1108

1109

1110

1111

1112

1113

1114

1115

1116

1117

Shuttleworth, W.J., 1976. Experimental evidence for the failure of the Penman-Monteith equation in partially wet conditions. Boundary-Layer Meteorology, 10(1): 91-94.

Shuttleworth, W.J., 1977. Comments on 'resistance of a partially wet canopy: Whose equation fails?'. Boundary-Layer Meteorology, 12(3): 385-386.

Shuttleworth, W.J., 2012. Terrestrial hydrometeorology. John Wiley \& Sons.

Shuttleworth, W.J. and Calder, I.R., 1979. Has the Priestley-Taylor equation any relevance to forest evaporation? Journal of Applied Meteorology, 18(5): 639-646.

Staudt, K. and Foken, T., 2007. Documentation of reference data for the experimental areas of the Bayreuth Centre for Ecology and Environmental Research (BayCEER) at the Waldstein site. Arbeitsergebnisse, 35. Universität Bayreuth, Abt. Mikrometeorologie, ISSN 1614-8916, Bayreuth, Germany, $35 \mathrm{pp}$.

Stewart, J.B., 1977. Evaporation from the wet canopy of a pine forest. Water Resources Research, 13(6): 915-921.

Stoy, P.C. et al., 2006. An evaluation of models for partitioning eddy covariance-measured net ecosystem exchange into photosynthesis and respiration. Agricultural and Forest Meteorology, 141(1): 2-18.

Stoy, P.C. et al., 2013. A data-driven analysis of energy balance closure across FLUXNET research sites: The role of landscape scale heterogeneity. Agricultural and forest meteorology, 171: 137-152.

Stull, R., 2011. Wet-Bulb Temperature from Relative Humidity and Air Temperature. Journal of Applied Meteorology and Climatology, 50(11): 2267-2269.

Tedeschi, V. et al., 2006. Soil respiration in a Mediterranean oak forest at different developmental stages after coppicing. Global Change Biology, 12(1): 110-121.

Thom, A.S., 1975. Momentum, Mass and Heat Exchange of Plant Communities. In: J.L. Monteith (Editor), Vegetation and the Atmosphere. Academic Press, London, pp. 57-109.

Thomas, C.K. et al., 2009. Seasonal hydrology explains interannual and seasonal variation in carbon and water exchange in a semiarid mature ponderosa pine forest in central Oregon. Journal of Geophysical Research: Biogeosciences (2005-2012), 114(G4).

Urbanski, S. et al., 2007. Factors controlling $\mathrm{CO}_{2}$ exchange on timescales from hourly to decadal at Harvard Forest. Journal of Geophysical Research: Biogeosciences (2005-2012), 112(G2).

Valente, F., David, J.S. and Gash, J.H.C., 1997. Modelling interception loss for two sparse eucalypt and pine forests in central Portugal using reformulated Rutter and Gash analytical models. Journal of Hydrology, 190(1-2): 141-162.

Van der Tol, C., Gash, J.H.C., Grant, S.J., McNeil, D.D. and Robinson, M., 2003. Average wet canopy evaporation for a Sitka spruce forest derived using the eddy correlation-energy balance technique. Journal of Hydrology, 276(1-4): 12-19. 
1118

1119

1120

1121

1122

1123

1124

1125

1126

1127

1128

1129

1130

1131

1132

1133

1134

1135

1136

1137

1138

1139

1140

1141

1142

1143

1144

1145

1146

1147

1148

1149

1150

1151

1152

1153

Van Dijk, A.I.J.M. and Bruijnzeel, L.A., 2001a. Modelling rainfall interception by vegetation of variable density using an adapted analytical model. Part 1. Model description. Journal of Hydrology, 247(3-4): 230-238.

Van Dijk, A.I.J.M. and Bruijnzeel, L.A., 2001b. Modelling rainfall interception by vegetation of variable density using an adapted analytical model. Part 2. Model validation for a tropical upland mixed cropping system. Journal of Hydrology, 247(3-4): 239-262.

Van Dijk, A.I.J.M., Peña-Arancibia, J.L. and Bruijnzeel, L.A., 2012. Land cover and water yield: inference problems when comparing catchments with mixed land cover. Hydrology and Earth System Sciences, 16(9): 3461-3473.

Van Dijk, A.I.J.M. and Warren, G.A., 2010. AWRA Technical Report 4. Evaluation Against Observations, WIRADA / CSIRO Water for a Healthy Country Flagship, Canberra.

Wallace, J. et al., 2013. Evaluation of forest interception estimation in the continental scale Australian Water Resources Assessment-Landscape (AWRA-L) model. Journal of Hydrology, 499: 210223.

Wallace, J. and McJannet, D., 2006. On interception modelling of a lowland coastal rainforest in northern Queensland, Australia. Journal of Hydrology, 329(3): 477-488.

Wang, W., Liang, S. and Meyers, T., 2008. Validating MODIS land surface temperature products using long-term nighttime ground measurements. Remote Sensing of Environment, 112(3): 623-635.

Williams, C.A. et al., 2012. Climate and vegetation controls on the surface water balance: Synthesis of evapotranspiration measured across a global network of flux towers. Water Resources Research, 48(6).

Wilson, K. et al., 2002. Energy balance closure at FLUXNET sites. Agricultural and Forest Meteorology, 113(1-4): 223-243.

Wilson, K.B. and Baldocchi, D.D., 2000. Seasonal and interannual variability of energy fluxes over a broadleaved temperate deciduous forest in North America. Agricultural and Forest Meteorology, 100(1): 1-18.

Wohlfahrt, G. et al., 2008. Seasonal and inter-annual variability of the net ecosystem $\mathrm{CO}_{2}$ exchange of a temperate mountain grassland: Effects of weather and management. Journal of Geophysical Research: Atmospheres, 113(D8): D08110.

Yan, Y. et al., 2008. Closing the carbon budget of estuarine wetlands with tower-based measurements and MODIS time series. Global Change Biology, 14(7): 1690-1702.

Zha, T. et al., 2010. Interannual variation of evapotranspiration from forest and grassland ecosystems in western Canada in relation to drought. Agricultural and Forest Meteorology, 150(11): 1476-1484. 
1154 Table 1. Measured energy balance for tall and short vegetation, during periods with and without rainfall,

1155 respectively. Listed are mean net radiation $\left(R_{n}\right)$, ground heat flux $(G)$, eddy-covariance derived sensible $\left(H_{E C}\right)$

1156 and latent heat flux $\left(\lambda E_{E C}\right)$, as well as the energy balance residual between the four terms and the energy balance

1157 ratio (EBR), the latter calculated as the ratio $(\lambda E+H) /(R n-G)$. Heat storage in the canopy was not considered in

1158 this case. Mean values were calculated as the simple mean for half-hourly intervals with and without

1159 precipitation at each site (based on a $0.25 \mathrm{~mm}$ threshold). Numbers listed represent the mean and standard

1160 deviation across sites with tall vegetation $(>3 \mathrm{~m})$ and short vegetation $(<1.5 \mathrm{~m})$, respectively $(20$ out of 128 sites

1161 has intermediate vegetation height or lacked sufficient data and were not included). Positive and negative signs

1162 here follow FLUXNET conventions (i.e., upward and downward, respectively).

\begin{tabular}{llcccccc}
\hline & & $R_{n}$ & $G$ & $H_{E C}$ & $\lambda E_{E C}$ & Residual & EBR \\
& & $\mathrm{W} \mathrm{m}^{-2}$ & $\mathrm{~W} \mathrm{~m}^{-2}$ & $\mathrm{~W} \mathrm{~m}^{-2}$ & $\mathrm{~W} \mathrm{~m}^{-2}$ & $\mathrm{~W} \mathrm{~m}^{-2}$ & - \\
tall vegetation & dry & $89 \pm 24$ & $-1 \pm 2$ & $35 \pm 21$ & $37 \pm 15$ & $16 \pm 13$ & $0.80 \pm 0.16$ \\
$(>3 \mathrm{~m}, N=59)$ & rainfall & $31 \pm 21$ & $2 \pm 8$ & $-12 \pm 16$ & $17 \pm 15$ & $28 \pm 20$ & $-0.37 \pm 1.92$ \\
& & & & & & & \\
short vegetation & dry & $70 \pm 26$ & $-1 \pm 3$ & $20 \pm 17$ & $38 \pm 18$ & $11 \pm 13$ & $0.86 \pm 0.32$ \\
$(<1.5 \mathrm{~m}, N=49)$ & rainfall & $23 \pm 18$ & $6 \pm 11$ & $-6 \pm 8$ & $17 \pm 14$ & $18 \pm 17$ & $0.36 \pm 0.56$ \\
\hline
\end{tabular}

1163

1164

1165

1166 
1168 Table 2. Proposed explanations for the discrepancy between wet canopy evaporation $(E)$ inferred through the

1169 water budget method and conventional Penman-Monteith approach $\left(E_{P M}\right)$. The implications for $E_{P M}$ and water

1170 budget derived interception loss $(I)$ are indicated.

Proposed explanation

Implication

$E_{P M}$ correct $\quad I$ correct

Errors in applying Penman-Monteith theory

Energy advection not accounted for

unclear yes

Biomass heat release underestimated

no yes

Errors in air humidity measurement

no yes

Aerodynamic conductance underestimated

no yes

Mechanical transport not accounted for

yes

yes

Errors in applying rainfall interception models

Canopy storage capacity underestimated

yes yes

Rainfall rate overestimated

yes

yes

1171

1172 
1173 Table 3. Estimated energy balance during rainfall for tall and short vegetation. For comparison, eddy-covariance 1174 based values reported in the FLUXNET database are also listed. Values were calculated as in Table 1, but in

1175 addition to $\mathrm{H}$ and $\lambda \mathrm{E}$ values reported in the FLUXNET database (subscript 'EC') were also calculated using the 1176 Penman-Monteith equation with best available inputs ('PM') and the more conventional application ('PMo'),

1177 both described in the text (all are in $\mathrm{W} \mathrm{m}^{-2}$ ). Meaning of symbols is as in Table 1, but positive and negative

1178 numbers here indicate incoming energy (gains) and outgoing energy (losses), respectively. The number of sites

1179 is slightly smaller than those used in Table 1 due to data availability.

\begin{tabular}{lcccccccc}
\hline & $R_{n}$ & $G$ & $Q$ & $H_{P M}$ & $\lambda E_{P M}$ & $H_{E C}$ & $\lambda E_{E C}$ & $\lambda E_{P M O}$ \\
tall vegetation & & & & & & & & \\
$(>3 \mathrm{~m}, \mathrm{~N}=57)$ & $31 \pm 22$ & $2 \pm 8$ & $29 \pm 31$ & $39 \pm 40$ & $-102 \pm 94$ & $12 \pm 17$ & $-17 \pm 15$ & $-93 \pm 84$ \\
short vegetation & & & & & & & & \\
$(<1.5 \mathrm{~m}, \mathrm{~N}=46)$ & $24 \pm 18$ & $7 \pm 11$ & $1 \pm 1$ & $17 \pm 20$ & $-48 \pm 28$ & $5 \pm 9$ & $-18 \pm 14$ & $-47 \pm 26$ \\
\hline
\end{tabular}

1180

1181 
1183 Table 4. Mean wet canopy evaporation rate $(E)$ and rainfall rate $(R)$ and their ratio $\bar{E} / \bar{R}$ as calculated from the 1184 simulation results for 83 sites using an intermediate canopy rainfall storage capacity estimate of $S=1 \mathrm{~mm}$.

\begin{tabular}{lccc}
\hline & rainfall half-hours & event-average & drying out phase \\
\hline mean $E\left(\mathrm{~mm} \mathrm{~h}^{-1}\right)$ & $0.15 \pm 0.13$ & $0.17 \pm 0.11$ & $0.33 \pm 0.17$ \\
mean $R\left(\mathrm{~mm} \mathrm{~h}^{-1}\right)$ & $1.62 \pm 0.82$ & $1.04 \pm 0.63$ & \\
mean $E /$ mean $R$ & $0.11 \pm 0.11$ & $0.19 \pm 0.12$ & \\
\hline
\end{tabular}

1185

1186 
1187

\section{8}

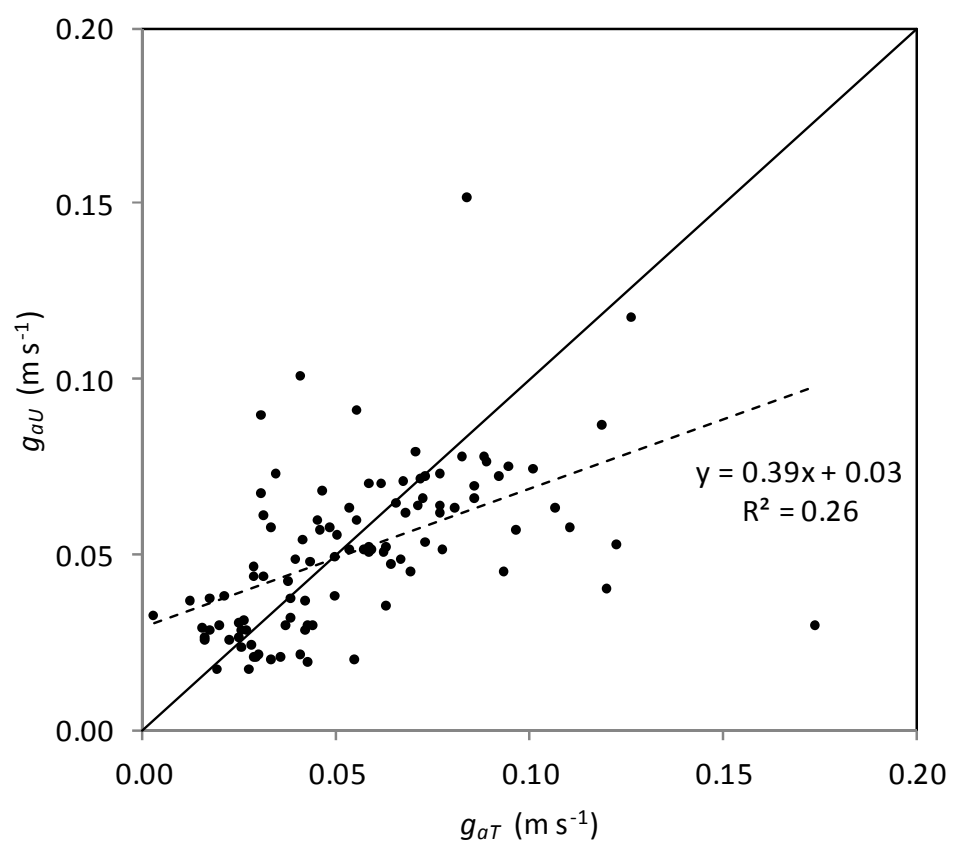

1189 Figure 1. Comparison between aerodynamic conductance during rainfall calculated from measured friction 1190 velocity $\left(g_{a U}\right)$ and estimated following Thom $\left(g_{a T}\right)$ for all vegetation types $(N=102)$. 

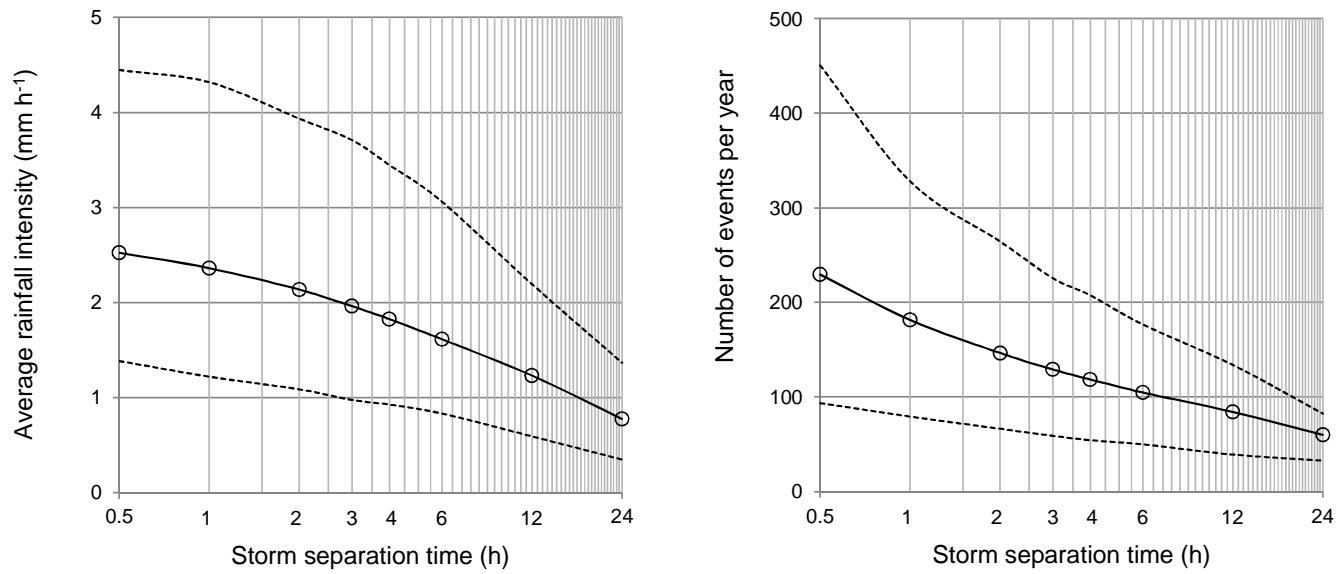

1192

1193 Figure 2. Relationship between storm separation time and (a) mean event-average rainfall rate $(R)$ and

1194 (b) number of rainfall events per year. Solid line represents mean of all sites, dotted lines show the

$119590 \%$ range $(N=184)$.

1196

1197 


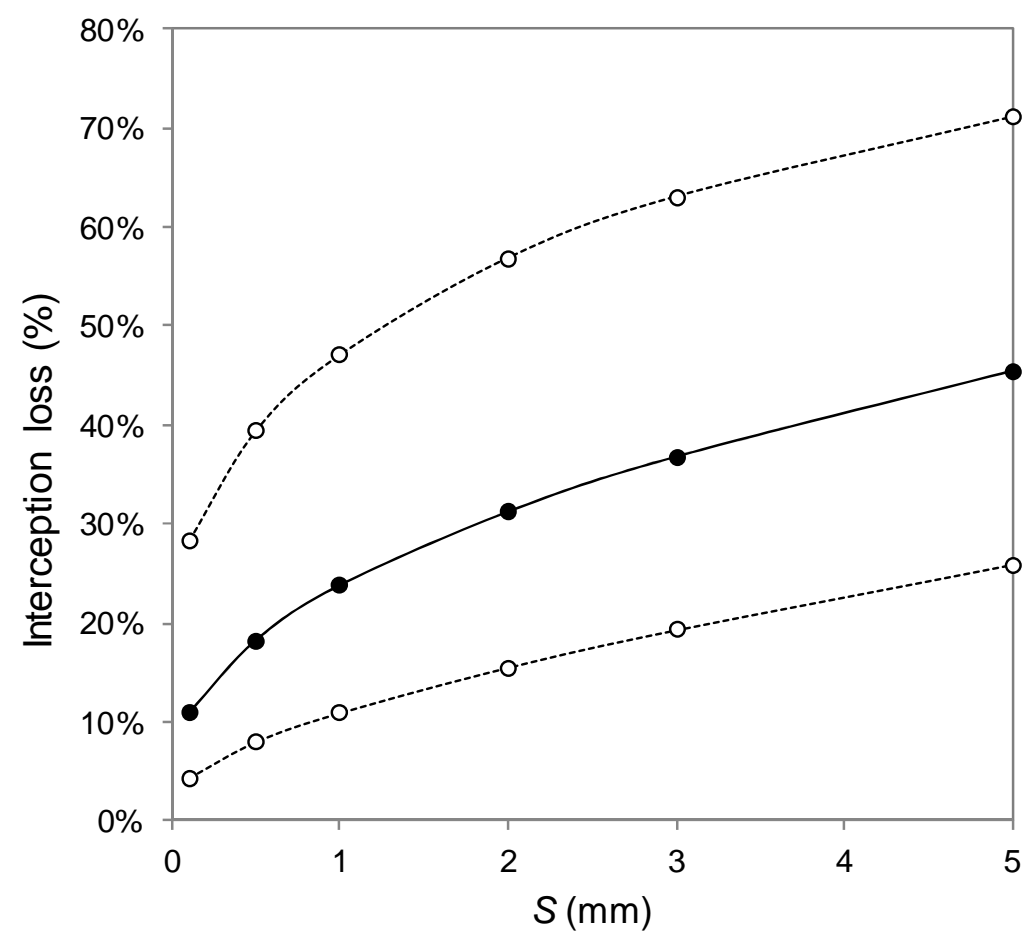

1198

1199 Figure 3. Influence of canopy rainfall storage capacity $(S)$ on interception loss (\% of rainfall) simulated with the 1200 simplified model of Rutter et al. (1971). Solid line and circle shows average for 82 sites; open dots and dashed 1201 lines bound the $90 \%$ range. 

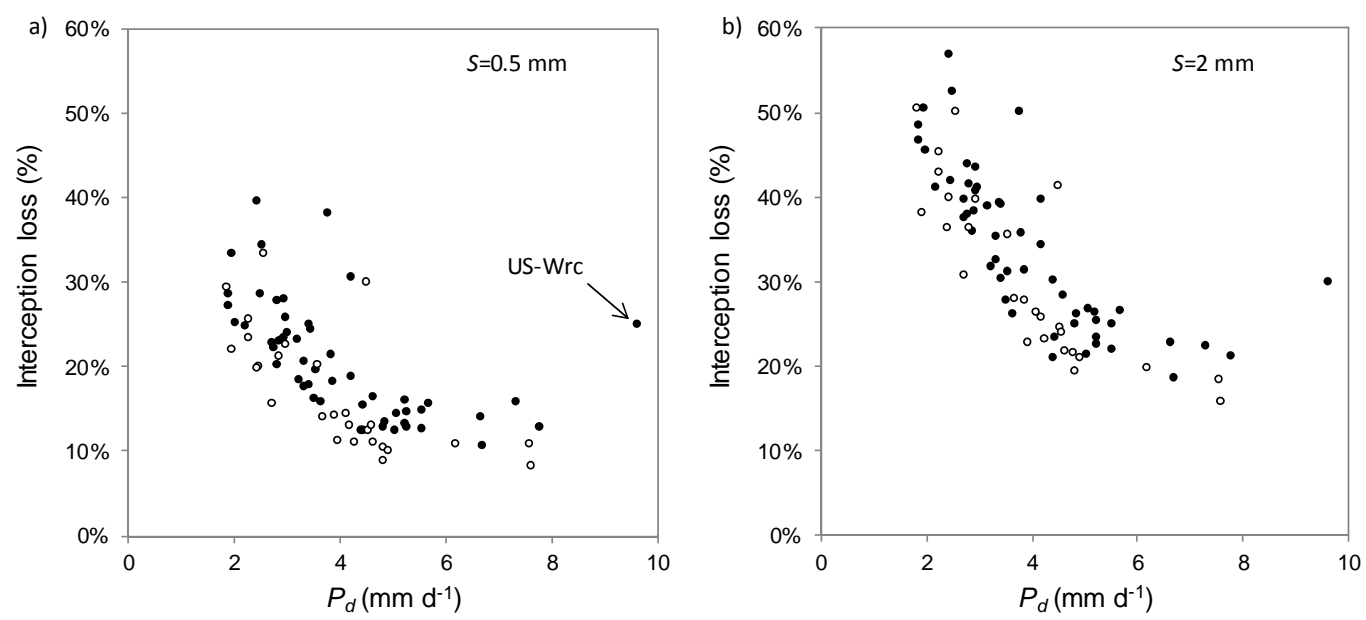

1204 Figure 4. Relationship between the average precipitation per rain day $\left(P_{d}\right)$ and model-simulated rainfall 1205 interception loss (\% of rainfall) for 83 FLUXNET sites. Interception was simulated using a simplified version 1206 of the model of Rutter et al. (1971) by assuming a canopy storage capacity (S) of (a) $0.5 \mathrm{~mm}$ and (b) $2 \mathrm{~mm}$. 1207 Open circles are for short vegetation $(<1.5 \mathrm{~m})$, solid circles for tall vegetation $(>3 \mathrm{~m})$. 